\title{
A review on frequency support provision by wind power plants: current and future challenges
}

\author{
A. B. Attya ${ }^{1}$, J.L. Dominguez-Garcia ${ }^{2}$, O. Anaya-Lara ${ }^{1}$ \\ Department of Electronic and Electrical Engineering, University of Strathclyde, Glasgow UK \\ Electrical Engineering Department, Catalonia Institute for Energy Research, Sant Adrià de Besòs, Spain
}

\begin{abstract}
The continuing increase of wind energy penetration in power systems, in combination with the retirement of conventional generation, raises new challenges for the maintenance of power system stability. This paper presents a comprehensive review of wind power plant capabilities to provide frequency support and the corresponding methods available in the published literature are thoroughly analysed and compared. The topic is covered from different perspectives giving a comprehensive overview of the work carried out in this field. In addition, the integration of energy storage technologies and dispatching of wind farms during frequency deviations are investigated. Finally, technical challenges, future research lines and general recommendations are provided.
\end{abstract}

Keywords - Wind power, frequency stability, power systems, energy storage, HVDC transmission

\section{Nomenclature}

\begin{tabular}{|c|c|c|c|}
\hline WS & Wind speed & $\mathrm{C}_{\mathrm{p}}$ & Performance coefficient \\
\hline WF & Wind farm & SOs & System Operators \\
\hline WTG & Wind turbine generator & $\mathrm{M}_{\mathrm{v}}$ & Special gain of virtual inertia \\
\hline A & WTG swept rotor Area & $\mathrm{H}_{\mathrm{v}}$ & Virtual inertia \\
\hline $\mathrm{R}$ & WTG rotor radius & $\mathrm{K}_{\mathrm{ill}}$ & Phase-Locked Loop integral gain \\
\hline DFIG & Double Fed Induction Generator & $\mathrm{P}_{\mathrm{cmd}}$ & Power command for WTG \\
\hline MPT & Maximum Power Tracking & SOC & State-of-Discharge \\
\hline $\mathrm{T}$ & Time interval & DOD & Depth-of-Discharge \\
\hline $\mathrm{P}$ & Active power & $h$ & Water level in the HPES reservoir \\
\hline $\mathrm{KE}$ & Kinetic Energy & fw & Flywheel \\
\hline$\Delta \mathrm{f}$ & Frequency deviation & $\mathrm{n}_{\mathrm{fw}}$ & Number of flywheels \\
\hline $\mathrm{H}$ & Inertia constant in seconds & $\mathrm{P}_{\mathrm{fw}}^{*}$ & Injected/absorbed power by flywheels \\
\hline PLL & Phase-Locked Loop & $\begin{array}{l}\mathrm{P}_{\mathrm{WTG}-} \\
\text { MPT }\end{array}$ & WTG output at MPT \\
\hline$\lambda$ & Tip-Speed ratio & $\mathrm{P}_{\mathrm{M} . \mathrm{A}}$ & $\begin{array}{l}\text { Moving average of } \mathrm{P}_{\mathrm{WTG}-\mathrm{MPT}} \text { in a time } \\
\text { interval }\end{array}$ \\
\hline BB & Battery Bank & $\mathrm{N}$ & Number of WTGs/WF \\
\hline$\omega$ & WTG rotational speed & $\mathrm{P}_{\mathrm{cmd}-\mathrm{WF}}$ & Power command for WF \\
\hline
\end{tabular}


HPES Hydro-pumped energy storage LIDAR Light detection and ranging

RoCoF Rate-of-change of frequency

\section{Introduction}

The energy policies of various countries, and also strategies by leading companies, highlight that the future is reserved for renewable energy sources, e.g. wind energy, as alternatives to address the electricity supply challenges in order to mitigate carbon emissions and present a competitive alternative for expensive fossil fuels. Wind Europe (formerly EWEA) reveals optimistic plans to integrate a massive number of wind farms (WFs) in the North Sea [1-5]. Similarly, the Danish government has ambitious targets to achieve 50\% wind power generation capacity by 2050 [6]. Germany is also progressing in a challenging plan to take out of operation all its nuclear power plants, and construct an additional $40 \mathrm{GW}$ of wind power capacity within the next few years to achieve this target, [7].

The expected high penetration levels of wind power into power systems, together with the increase of other power electronics-based technologies (i.e. energy storage, high voltage direct links (HVDC), PV farms, etc.) and the retirement of conventional synchronous plant will introduce power system stability issues. A major challenge will be the reduction of the total inertia, which will result in highly fluctuating and fragile dynamic responses. Accordingly, transmission system operators (TSOs) are developing new grid codes requiring contributions not only from conventional generators but also from renewable energies and power electronicsbased technologies (e.g. HVDC). On this matter, ENTSO-e has published an initial draft of its first HVDC code [8, 9].

Several issues related to the role of wind power in ancillary services have been discussed in the literature, including voltage and frequency support [10]. In this context, this paper focuses on the active power contribution of wind turbines (WTGs) and WFs to suppress frequency drops. The theory of frequency support is based on the provision of an active power surge during the frequency event to mitigate the generation-demand unbalance. Securing stable energy resources and managing this power surge are key challenges that need to be addressed [11]. In [12], frequency metrics and grid code requirements were reviewed, meanwhile this review paper focuses on the technical aspects and the wide range of the control algorithms proposed in the literature. This paper also discusses the dispatching of WFs/WTGs during frequency events. An additional contribution is an investigation of indirect methods that enable wind power plants to provide frequency support, markedly energy storage systems. This review also 
highlights the potential role of HVDC links, which is a promising technology to connect the offshore WFs, with frequency support capabilities.

\subsection{Problem definition}

Conventional generators have two critical and one supplementary response to frequency variations; inertia response and primary response are illustrated in Figure 1, and further definitions for load-frequency regulation could be found in [13]. The first is a natural reaction to the sudden drop in system frequency that results in an instantaneous decrease in the mechanical speed of the turbine-generator set (inertia). The inertia response is the extraction of kinetic energy $(\mathrm{KE})$ stored in the rotating parts of the turbine and generator. $\mathrm{KE}$ is depleted to increase the mechanical output power of the WTG to achieve the balance between the electrical demand and mechanical output so that the speed stabilizes at a new slower synchronous speed. However, the deceleration reaction (KE extraction) has a threshold that relies on the inertia constant of the plant $(\mathrm{H}$; typical values from 4 to $7 \mathrm{~s})$, and the nominal frequency of the grid $[14,15]$. The second response is proportional to the frequency drop severity according to the assigned droop value [14]. The third one is not as critical to system stability as the other two, but it should achieve a complete balance between generation and demand to recover the frequency to the safe deadband.

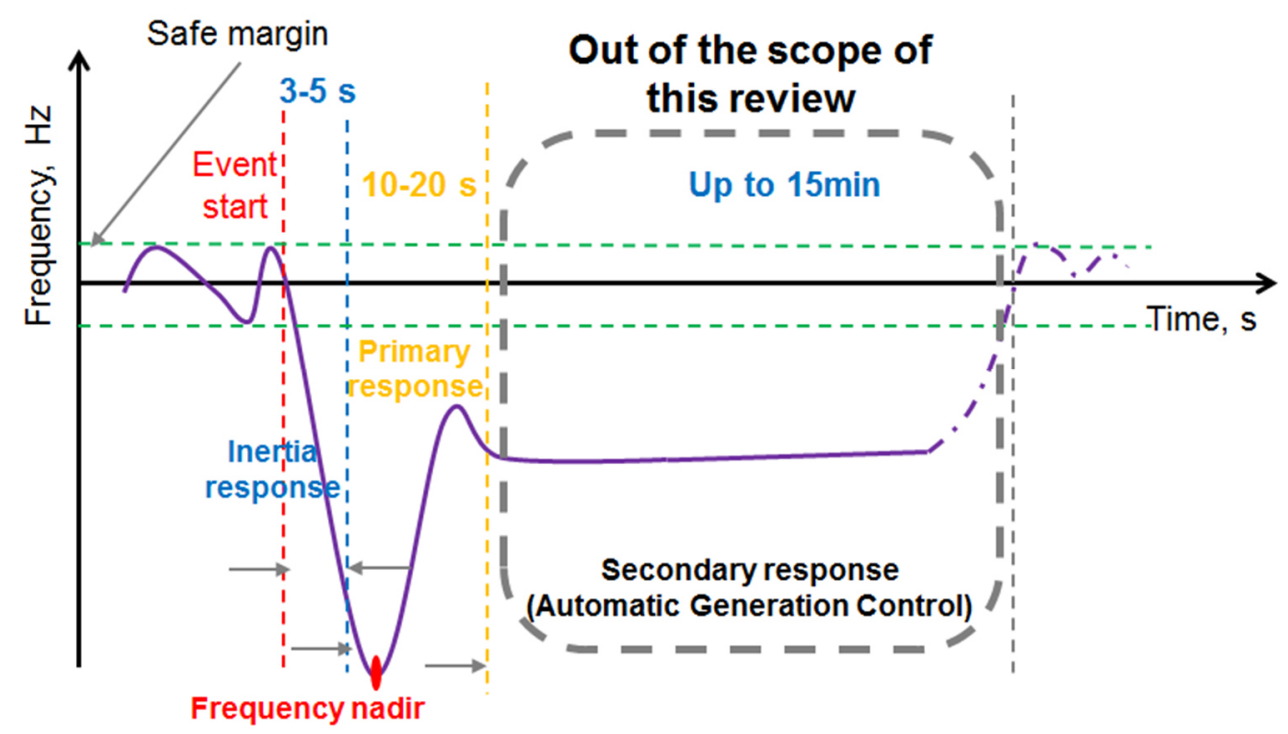

Figure 1 The main responses provided by power plants to intercept and mitigate frequency drops.

The literature proposes three major concepts to obtain the former two responses directly from WTGs, namely 1) emulated (i.e. Synthetic) inertia, 2) droop and de-loading techniques, as well as 3) WTG overloading (i.e. bring the generator output to its threshold when wind speeds (WSs) 
are above their rated values). This type of support could also be carried out by Energy Storage Systems to avoid the integration of special supplementary control methods into WTGs [16]

Another aspect of frequency stability, which is out of scope of this paper, is the over-frequency, and it can be solved by the reduction of wind power generation when the frequency deviations violate certain limits. This aspect has been considered on a limited scale, compared to underfrequency support. It is of note that, the majority of frequency support methods can also regulate the WTG output during over-frequency events $[17,18]$.

\section{Synthetic inertia}

All renewable power generation technologies (except conventional hydro power plants) are decoupled from the grid through a power electronics (PE) interface that screens any variations in grid frequency due to the very fast response of the PE devices. Hence, the WTG cannot respond naturally to frequency drops although it has reasonable inertia which is comparable to that of conventional generators (i.e. WTGs do have stored KE as they include rotating masses, but they do not sense the sudden drop in grid frequency because the converters react very fast and alternate the control signals $[19,20])$. Here we consider how an artificial (it is also called synthetic and virtual) inertia response can be produced by variable-speed WTGs, specifically, type-3 Doubly-Fed Induction Generator (DFIG) and type-4 Fully-Rated Converter Generator. In order to answer this question, it should be highlighted that the conventional operation of WTGs is based on Maximum Power Tracking (MPT), where the rotor speed is controlled to maintain the optimum performance coefficient $\left(\mathrm{C}_{\mathrm{P}}\right)$ which is the portion of energy available in the wind extracted by the rotor, given by (1)

Mechanical output power $=\frac{1}{2} \cdot \rho \cdot C_{p}(\lambda, \beta) \cdot \mathrm{A} \cdot W S^{3}$

where $\lambda, \beta, A$, and $\rho$ are the tip-speed ratio, blades pitch angle, rotor swept area and air density respectively. This principle is illustrated in Figure 2, 


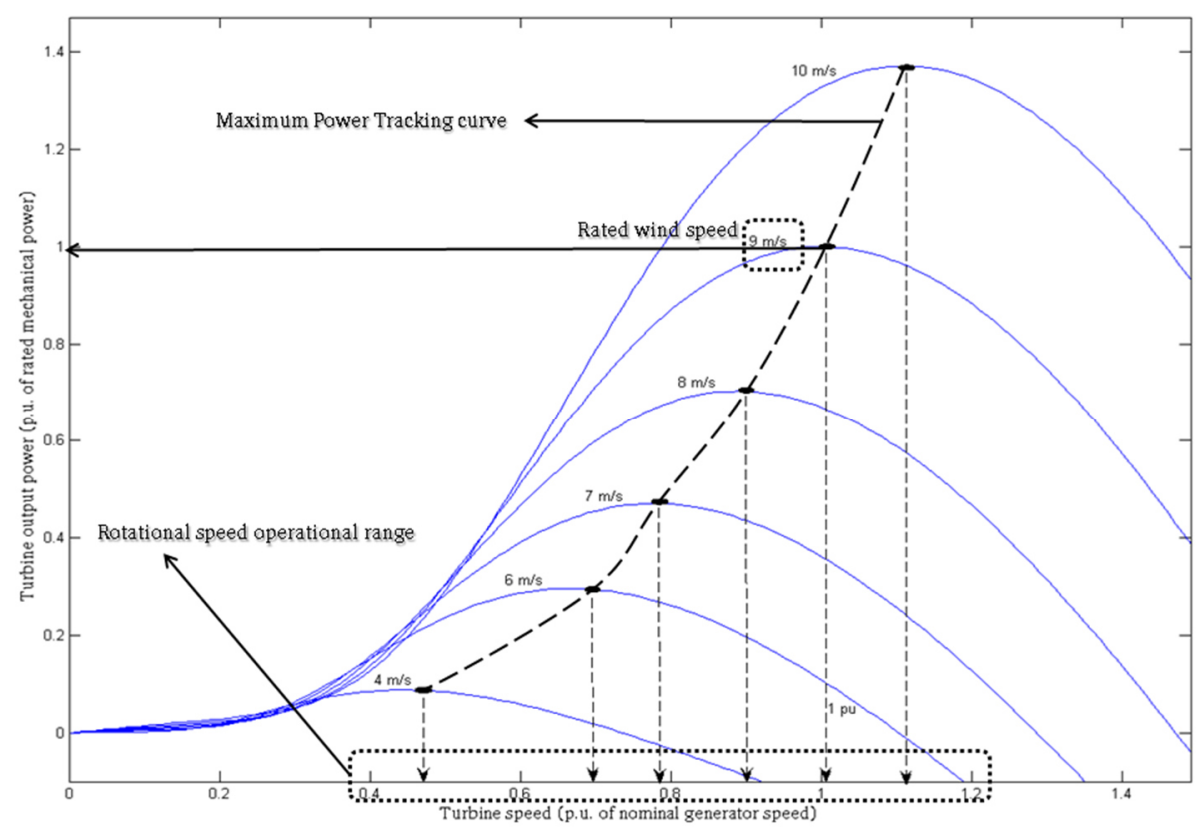

Figure 2 Typical MPT curve for a wind turbine generator.

The DFIG is connected to the grid through the stator only, and it is fully controlled through two converters: a Rotor Side Converter and a Grid Side Converter. The converter's capacities are typically $35 \%$ of the machine rated power. Type 4 uses a fully rated converter that completely decouples the WTG from the grid $[21,22]$. Neither type provides a natural inertia response in their conventional operation (i.e. MPT) due to the decoupling from the grid frequency. Moreover, at MPT, both types are already generating the maximum available power for the prevailing wind speed so there is no room to provide a supportive power surge. The expression 'synthetic' or 'emulated' inertia was coined to describe control algorithms that are used to provide an artificial inertia response. Note that the expression 'Synthetic' has been standardized to replace 'Emulated' according to [23].

The literature deals with two main aspects of KE extraction, first, proposing methods to extract $\mathrm{KE}$ during frequency events, and second, quantifying the available KE, whereby the quantification is highly dependent on the associated method of extraction. The following subsections present the two key methods to enable KE extraction.

\subsection{WTG deceleration}

The most common approach to extract KE in a WTG is to apply a slight increase in the reference electrical power (or reference electrical torque) so that the demanded power output is higher than that available from the wind. Consequently, the rotor slows down as KE is converted into electrical energy to deliver a power surge [23, 24]. This deceleration stops when 
the rotor speed reaches a certain limit to avoid loss of synchronism and stalling the turbine. This limit is around $70 \%$ of the WTG rated rotor speed corresponding to more than $50 \%$ of stored KE [25]. This procedure has the major advantage that the WTG does not deviate from the MPT during normal operation [26]. However, the WTG power output is lower after the $\mathrm{KE}$ extraction process is completed in order to recover the nominal rotor speed (i.e. acceleration process, where the supplied power should be lower than the available mechanical power). This recovery stage might trigger a second frequency drop if the dispatching of WTGs/WFs is not executed properly. Examples of this approach are available in [19] [25] [27]. The authors forced the WTG to decelerate by increasing the reference active power by a value denoted $\Delta \mathrm{P}_{\mathrm{KE}}$, hence converting the stored $\mathrm{KE}$ into a predefined output increase (WS is fixed during the frequency event) [25]. As an alternative, the reference torque could be modified according to the frequency deviation [28]. This approach is somehow similar to WINDINERTIA - a method developed by General Electric that applies a simplified controller, where the WTG is decelerated due to an excess power step initiated during frequency events [27]. The representation of the WTG inertial response was based on a single-mass lumped model guided by Newton's Law of Motion [25]. The deceleration process continued for a fixed duration independent of the speed reduction. This duration is determined based on an iterative procedure to assure that the minimum speed threshold is not violated.

The torque controller in [19] depended on the rate of change of frequency (RoCoF) as opposed to $\Delta f$ as in [25] [27], and the inertia response is tuned through the parameters of the PI controller as shown in Figure 3. High values of the PI time constant mean that the DFIG effectively sees a lower RoCoF than the true value, thus, the generator delivers a smaller inertia response for the same PI gain. The impact of the WTG operation point prior to the frequency event was discussed, and it was concluded that the PI gain must be scaled (normalized) at each event by multiplying it by the ratio of instantaneous rotor speed to the maximum rotor speed $\left(\omega / \omega_{\max }\right)$, which can be considered as simplified adaptive control. Consequently, the inertia response is independent of the operation conditions. Their recommendation was to evaluate the PI gain at rated speed using the aggregate inertia of the WTG $\left(\mathrm{H}_{\mathrm{WTG}}\right)$, where the PI gain $\approx 2 \cdot \mathrm{H}_{\mathrm{WTG}}$, and it was slightly higher in order to compensate the attenuation caused by PI time constant (PI gain $=13 \mathrm{~s}$ ). 


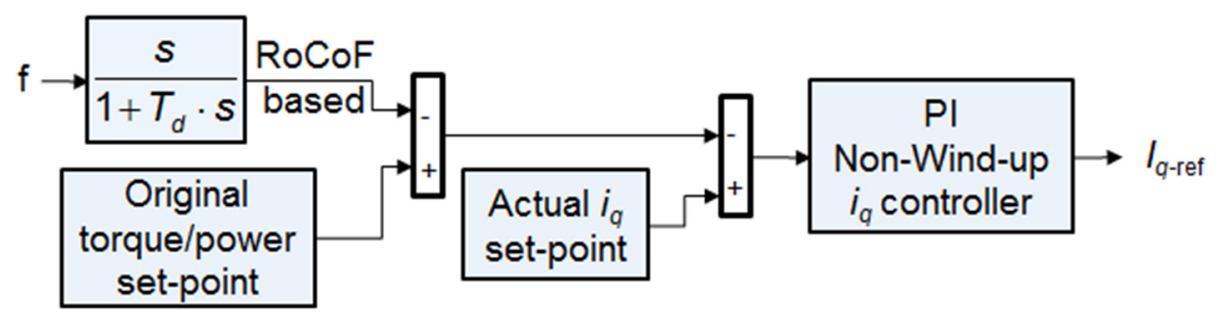

Figure 3 Proposed auxiliary controller in [19].

The inertia response is shaped by passing the system frequency through a special function to modify the reference slip [29]. The slip reference signal is responsible for setting the reference phase shift angle of the voltage behind the transient reactance of the machine. The variation of the WTG slip ratio is considered as an indirect method to control the rotor speed to provide inertia response through setting the phase shift of the rotor flux vector. The controller is relatively complicated due to the presence of the shaping transfer functions that needs additional tuning efforts according to the targeted inertia response, and the limitations of the WTG. Moreover, it might have an impact on the reactive power contribution of the WTG because it directly affects the rotor flux.

The extractable KE has been quantified through different approaches (i.e. statistical and dynamic simulations), and case studies in [24] [25] [30] [31]. The study in [24] provides a simple method to estimate the amount of extractable KE at a given WS, but the inertia of the WTG must be calculated first. A compromise between the supportive power step and the effective duration of support was also discussed. On average, a 0.2 p.u. power step lasts for 25 $\mathrm{s}$ for the examined WTG [24]. It was concluded that increasing the optimal tip-speed ratio $\left(\lambda_{\text {opt }}\right)$ extends the WTG support time before reaching the minimum rotor speed limit. Both [24] and [25] agreed that increasing the WTG nominal rotor speed and higher WTG inertia increase the supportive power surge or extend the support duration (given a fixed WS).

Another example of KE quantification is presented in [30] and is based on a case study using real 10-minute mean WSs at Irish WFs is used. The authors assumed a fixed inertia of 2.5 seconds for all WTGs, thereupon it was found, based on a probabilistic study, that when the generation is beyond $20 \%$ of the installed wind capacity, $90 \%$ of the WTGs have extractable KE. Additionally, a statistical analysis was performed to find the annual rate of occurrence of severe frequency nadir and steep RoCoF. Increasing DFIG wind power penetration (without conventional generators retirement) caused a negative impact on frequency nadir and RoCoF as shown in Figure 4. Compared to [30], [24] proposed a simple dynamic method to assess the extractable KE and then calculated the magnitude of the supportive power surge. Meanwhile, 
[30] used statistical data and a probabilistic approach to reach a round figure of the extractable KE of a group of WFs. Reference [31] presented a similar study for the Ireland-Northern Ireland power system and the possible penetration of variable-speed WTGs but the control parameters were not revealed. One of the major findings was the ability of a WTG to provide $0.5 \mathrm{MJ} / \mathrm{MW}$ within $10 \mathrm{~s}$ when WS is above minimum. In the power system studied, and due to the expansion of wind generation capacity from 1500 to $6000 \mathrm{MW}$ (replacement of conventional units in 2020), at 50\% cumulative hourly probability; the system inertia dropped from $38 \mathrm{GWs}$ to $28 \mathrm{GWs}$. The paper also compared between two levels of inertial contribution, where one of them needed longer recovery period. The probabilistic study at different levels of WS (from 5 to $14 \mathrm{~m} / \mathrm{s}$ ) with a time resolution of 15 minutes showed a huge variation of the availability of WTGs inertial response. The paper applied the WINDINERTIA concept and investigated the impact of different levels of wind penetration (max. penetration $75 \%$ ).

The authors of [32] estimated the extractable KE of two types of WTGs; Enercon 3 MW E101, and 2 MW E-82. They considered the size of the WF and the availability of the WTGs to determine the actual amount of extractable KE from a WF. The frequency dip severity was linked to the amount of energy, on per unit bases with respect to the European grid, in a bar chart. The occurrence rates of different dips' categories are also displayed in Figure 4, where dips worse than $70 \mathrm{mHz}$ represent only $10 \%$ of the occurrence of all events.
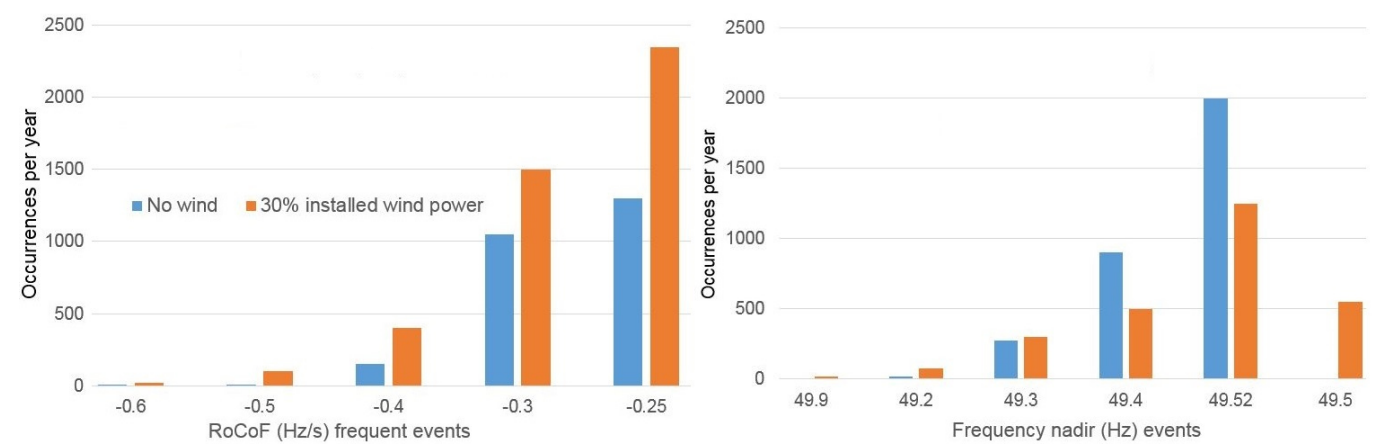

Figure 4 Changes in RoCoF and frequency nadir after wind power penetration [30].

Generally, the recovery stage (post frequency drop) might trigger further frequency drops because the WTG output is suddenly reduced to start the recovery process, which is the major weakness of this concept, and it was mitigated by a shaping function (simpler one compared to [29]) which applies a ramping (not a step) reduction in the WTG electrical output reference [33]. The shaping function is triggered automatically (independent of the drop severity) when the frequency violates the safe margin to trigger a step increase in the reference power signal of the WTG, as shown in Figure 5. When the frequency recovers to the safe margin, the power reference is reduced gradually through the shaping function. The parameters of this shaping 
function (e.g. ramp slope) were tuned using a four-part fitness function Particle Swarm Optimization technique. The first part applied high penalty on violating the system operation constraints (e.g. WTG rotor speed limits and overloading). The second, third and fourth parts considered the frequency nadir, the sum of the post-fault frequency square error, and RoCoF respectively. The paper provided details of the models and numerical values for several shaping functions which are a good asset for future work. Another approach was offered in [34] to mitigate transient energy loss and shorten recovery period where the optimum power was tracked during the rotor speed deceleration. The WTG inertia was not constant but a function of the rotor speed using (2),

$H_{W T G}(\omega)=\frac{1}{\omega} \frac{J_{W T G} \cdot \lambda^{3}{ }_{\text {optimum }}}{\rho \cdot A \cdot R^{3} \cdot C_{p-\text { optimum }}}$

where $\mathrm{J}_{\mathrm{WTG}}$ is the WTG moment of inertia and $\omega$ is the rotor speed. The proposed method achieved the same peak power surge compared to the conventional KE extraction method, and the rate of power surge decay was higher. The WTG over-speeding is also a solution to overcome recovery problems, as discussed in the next subsection.

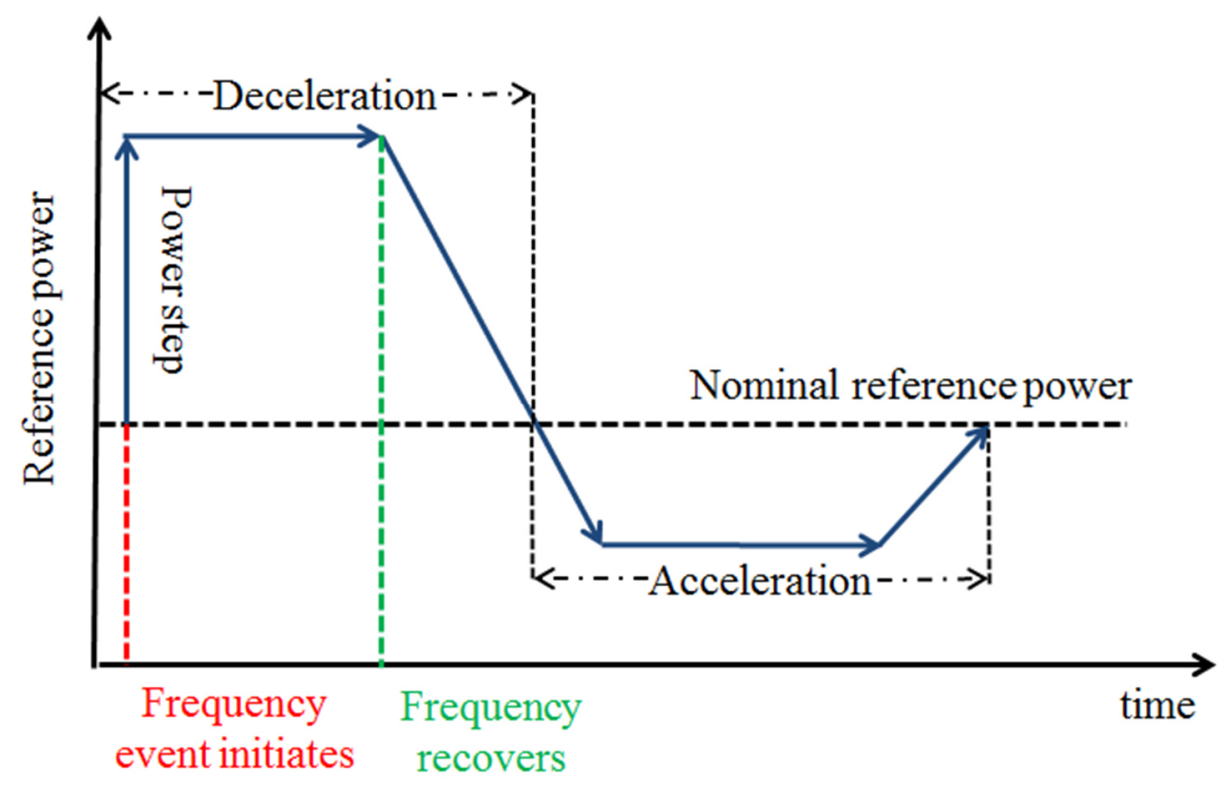

Figure 5 Illustration for the shaping function method.

\subsection{WTG over-speeding to provide inertial response}

'Over-speeding' is achieved by increasing the WTG rotor speed (or tip-speed ratio) through a supplementary control loop to a value higher than the nominal/optimal value (i.e. that leads to an optimum $\mathrm{C}_{\mathrm{p}}$ ), thus the WTG operation deviates from MPT. When the grid suffers a 
frequency drop, the rotor speed returns back to the nominal value, hence the WTG decelerates (KE extraction). The deceleration process stops when the speed reaches the nominal reference as shown in Figure 6. Therefore, when the frequency drop is cleared, there is no need to start a recovery stage immediately, and WTG continues providing its optimum power output. Afterwards, the over-speeding point is recovered gradually (i.e. not all the WTGs at the same time) to avoid further frequency events. The management of initializing/terminating frequency support technique among several WTGs in the same WF is called from now on 'Dispatching', and it is investigated in Section 5. The over-speeding technique leads to loss of wind energy at medium WS classes (i.e. MPT is violated) [26]. The major drawback of this method is its limited capability when the nominal speed approaches the highest threshold (i.e. at high WSs). The deceleration method explained in the previous subsection could be an alternative to secure a power surge especially that a relatively higher amount of KE is stored at high WSs because the rotor is running at higher speed. The basic concept of over-speeding is explained in [32].

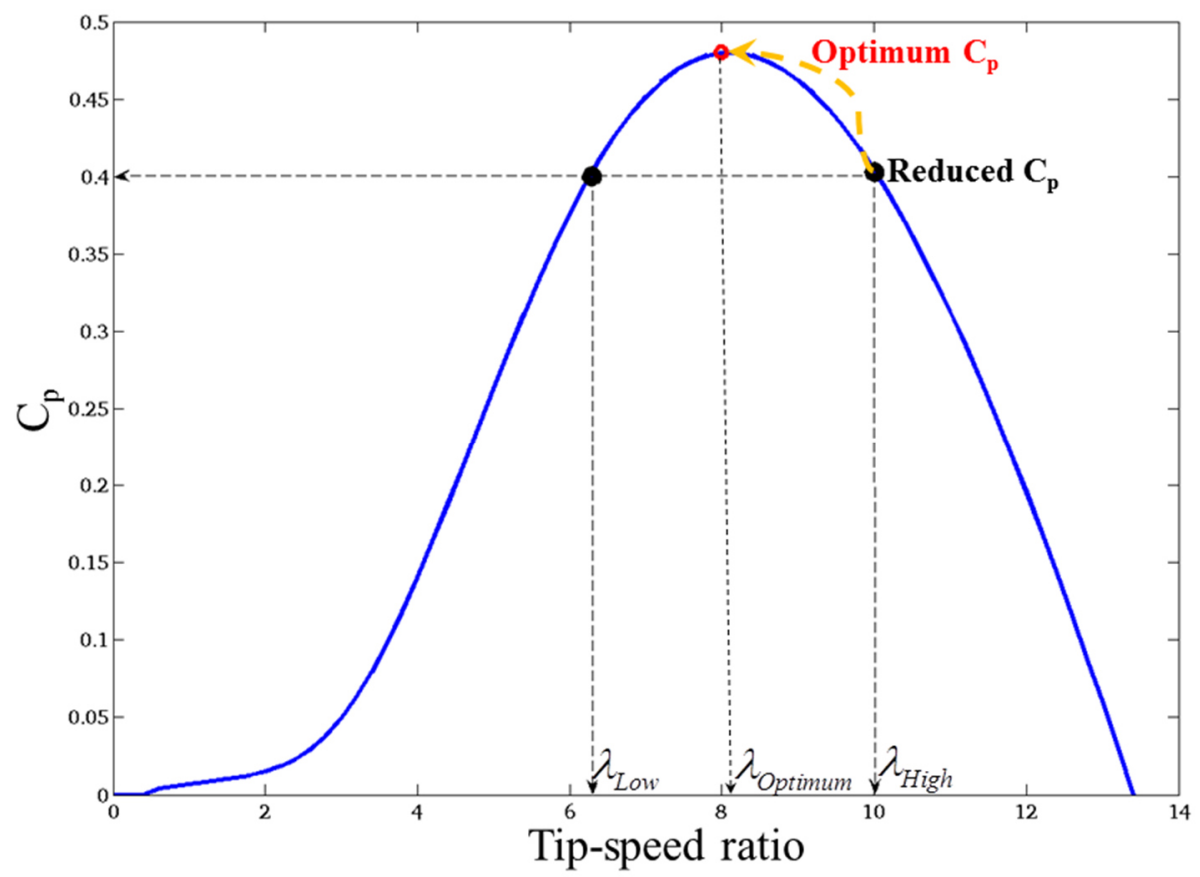

Figure 6 Over-speeding WTG to reach a higher tip-speed ratio and returns to optimum $C_{p}$ at frequency events.

The proposed over-speeding algorithms in [32] [35] are simplified based on a minor deviation in reference signals of speed or tip speed ratio. More complex methods alternate the voltage components, namely the q-axis voltage component $\left(v_{q}\right)$ of WTG [36] [37].

Virtual inertia $\left(\mathrm{H}_{\mathrm{v}}\right)$ was proposed in [36] where the reference electrical torque is reduced by a certain value obtained from a transfer function in (3), 
Electrical torque demand $=\omega_{\text {optimum }}-H_{v}\left(\omega_{m}\right)$

$H_{v}\left(\omega_{m}\right)=M_{v} \cdot K_{i, l l} \cdot \Delta v_{q}$

where $\mathrm{M}_{\mathrm{v}}, \mathrm{K}_{\mathrm{ill}}$ and $\Delta v_{q}$ are the pre-adjusted gain, Phase-Locked Loop (PLL) integral gain, and deviation in the $q$-axis voltage respectively. The transfer function has two poles, $\mathrm{M}_{\mathrm{v}}$ is preadjusted by trial and error to achieve acceptable stability, while the PLL is used to measure voltage. The authors simplified the term $\left(\mathrm{H}_{\mathrm{v}}(\mathrm{s}) \cdot \omega_{\mathrm{m}}\right)$ to be expressed in terms of $\Delta v_{q}$ which is already well defined in any WTG for use in the converters' controls. Therefore, the setting of $\mathrm{H}_{\mathrm{v}}$ poles is not required and the inertia response (i.e. the higher speed value in over-speeding) is adjusted through $\mathrm{M}_{\mathrm{v}}$. The authors examined this method on a simplified micro-grid system to be able to deduce the closed loop transfer function and draw the system root locus, and observed that increasing $\mathrm{M}_{\mathrm{v}}$ moves the poles far from the unstable margin.

The tuning of $v_{q}$ was also proposed in [37] in a simpler way based on the derivative of the KE available at a given speed, where it depended on rotor speed sensing instead of WS measurement. This derivative signal was then processed through a first-order filter to alleviate fast fluctuations. The demand electrical torque was then tuned, and thereupon $v_{q r}$ was changed as shown in Figure 7. However, [36] focused on assessing the controller stability, hence a simple benchmark system was integrated to focus on the controller dynamics. Root loci and Bode diagrams were presented to determine the stable ranges for the main parameters of the $\mathrm{H}_{\mathrm{v}}$ transfer function.

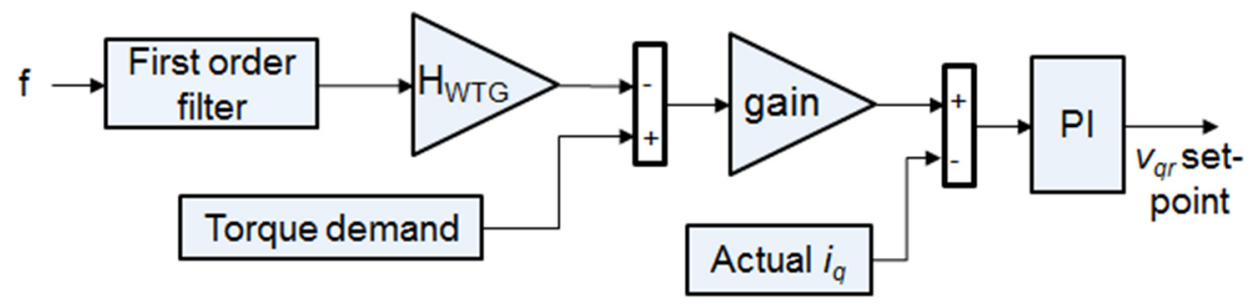

Figure 7 Controller offered in [37] to update $v_{q}$ based on turbine rotor speed.

The algorithm proposed in [35] merges the two concepts discussed above, namely, overspeeding and decelerating below optimum speed. This algorithm runs the WTG at a higher rotor speed which is determined according to a pre-set high tip-speed ratio $\left(\lambda_{\text {high }}\right)$. An acceptable accuracy level for WS measurement is required and min tip-speed ratio is preadjusted. Since the $C_{p}-\lambda$ curve is approximately symmetrical, the optimum tip speed ratio is the average value between high and min tip-speed ratios. Similar to the approach presented in [25], 
support time (i.e. the duration of power surge provision) is fixed. The recovery time was decided according to a piecewise linear function where it is assumed that the speed recovers to achieve $\lambda_{\text {high }}$ with a uniform rate as shown in Figure 8 . The deceleration and acceleration slopes are assumed to be equal and linear because they take short time. Note that the WTGs continue at $\lambda_{\min }$ as long as the frequency event prevails (from $t_{2}$ to $t_{3}$ ). The impact of the frequency severity was acknowledged where the frequency drop reflected the amount of required KE to maintain the grid frequency, in turn, the new lower speed (i.e. $\lambda_{\text {low }}$ ). This reduced the recovery time and mitigated the speed oscillations in the WTG until it recovers to $\lambda_{\text {high. }}$.

It should be highlighted that all the methods discussed in this section are suitable only to variable-speed WTGs, because the WTG requires the ability to operate within a predefined range of rotational speed above and/or below the nominal speed. However, fixed-speed WTGs, can provide frequency support through pitch control support methods [38], which are discussed in the next section.

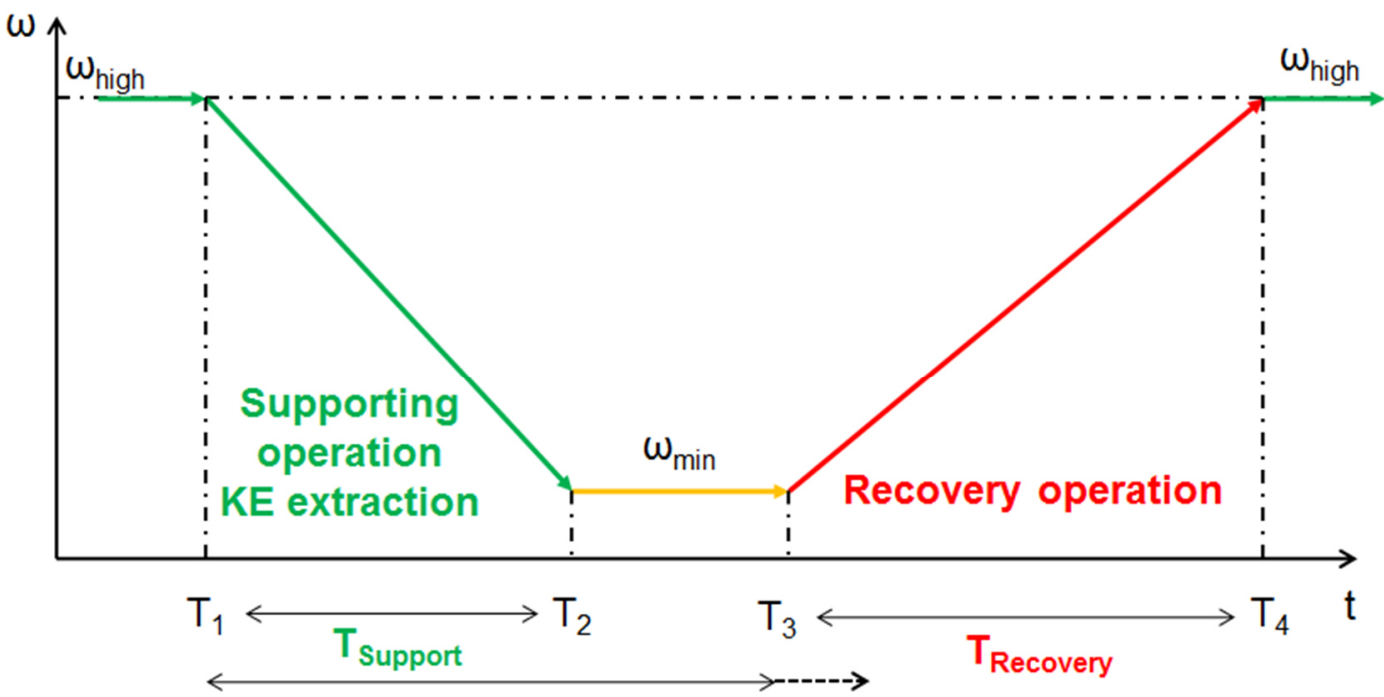

Frequency deviation period

Figure 8 rotational speed variations according to the algorithm proposed in [35]

\section{Governed primary response}

The primary response can be controlled in conventional generators through the droop setting. Droop is defined as the per unit change in generation, on machine capacity bases, with respect to $1 \mathrm{~Hz}$ change in frequency. The droop setting controls the governor responsible for steam feed (thermal power plants) or gate opening (hydropower plants). The challenge in wind power generators is how to integrate the same concept as the fuel powering WTGs, the wind, is uncontrollable. One of the proposed solutions is to apply the droop action using pitch control. The pitch angle $(\beta)$ is a major control parameter in the aerodynamic equation of $C_{p}$; increasing 
$\beta$ reduces the output mechanical power. In conventional operation, pitch control is used only to maintain output power and rotor speed within the limits of the machine. However, de-loaded pitching is widely used in droop control. The droop function is also applied through supplementary controllers integrated into the conventional controllers of WTG.

Firstly, it is important to define 'de-loading'; operating the WTG to provide less output power than the available in the wind flow (i.e. MPT is violated). De-loading has two types; Delta and Balance; in Delta the output power is reduced by a certain percentage of the available power, meanwhile in Balance mode the output is reduced to a fixed value (e.g. 0.2 per unit) [39]. At high WSs, in Balance mode, the WTG should provide fixed power and if the output, according to the MPT is higher, the WTG is de-loaded to maintain the pre-set fixed output as shown in Figure 9.

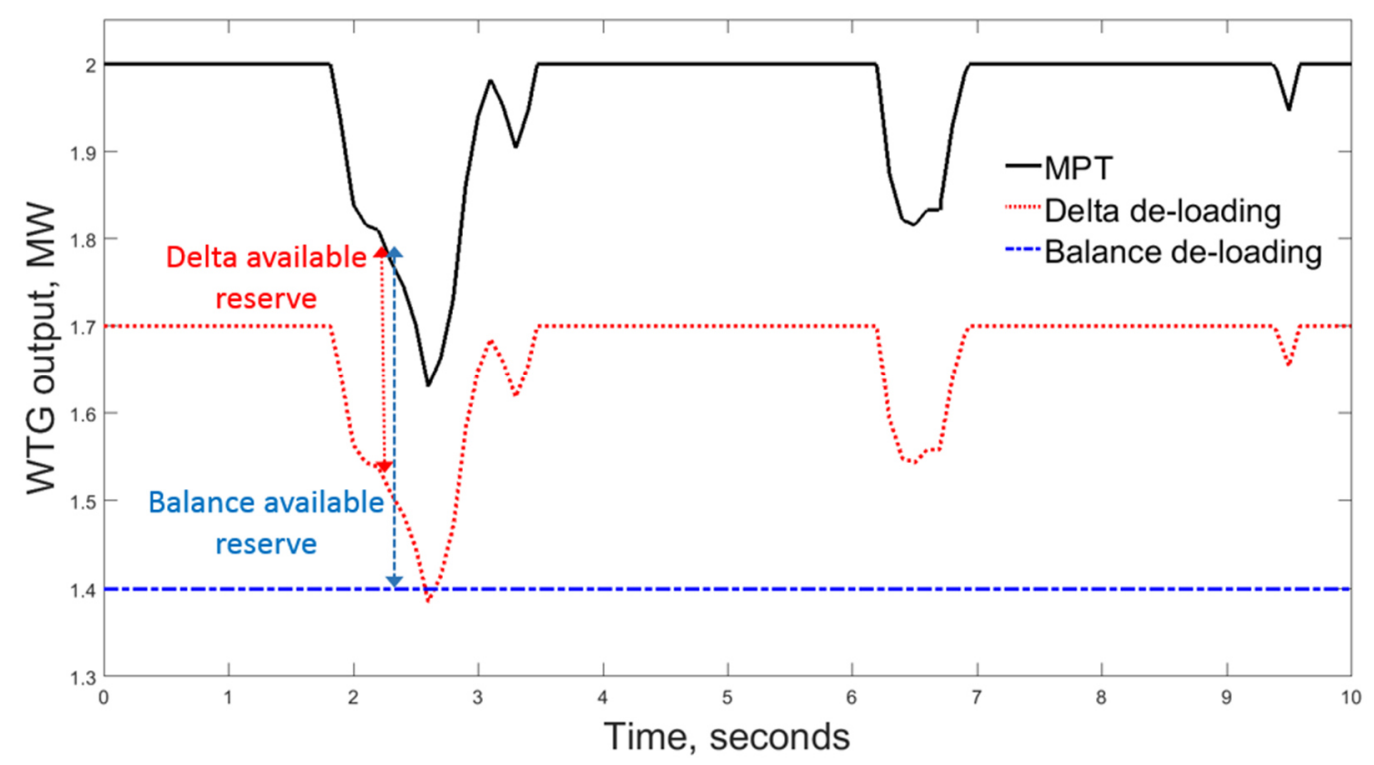

Figure 9 Example for Delta and Balanced de-loading techniques for a WTG [39].

The simplest way to de-load the WTG is by pitching the blades, where the reference power to the pitch controller [40] is to set a certain value that achieves the target de-loading level [4143]. The dominant de-loading ratio (Delta mode) ranges from $10 \%$ to $20 \%$ of the available wind power [44], where the average WS, rating of WTG, and expected level of frequency support are the main parameters taken into account. To overcome the problem of pre-adjusting the de-loading factor, a simple droop controller is presented in [45]. The WTG is operated according to a de-loaded P- $\omega$ curve. The system frequency is multiplied by certain droop to set the final reference output power signal as shown in Figure 10. Thus, the de-loading ratio is not 
fixed, but it varies according to frequency changes, which reduces the WTG output when the frequency is above nominal (i.e. full frequency regulation not only at frequency dips).

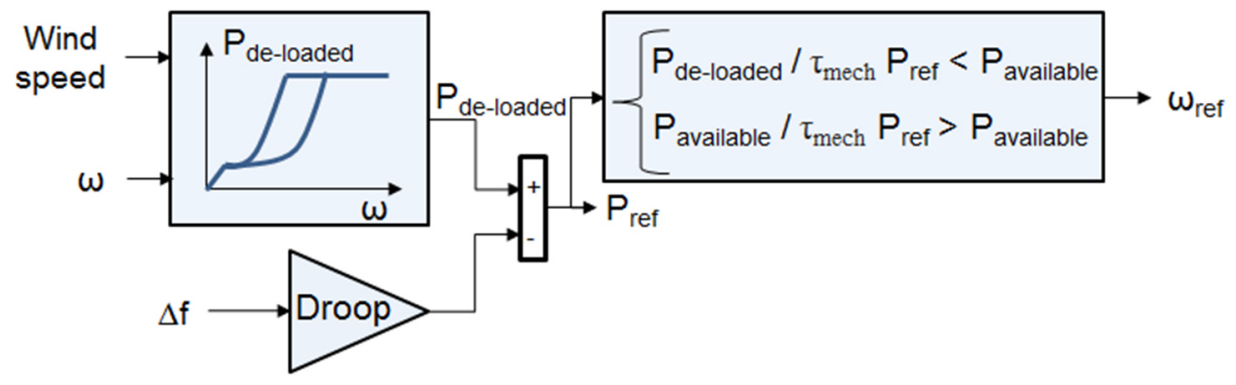

Figure 10 Proposed droop controller in [45].

The algorithm proposed in $[43,46]$ merges inertial and de-loading responses. In [46], at low WSs, the WTG receives a higher reference output than the available wind power, thus the WTG decelerates until a certain defined stopping speed $\left(\omega_{\text {stop }}\right)$ as in Figure 11. The adjustment of $\omega_{\text {stop }}$ is carried out for each frequency event through a look-up table. At WSs greater than rated, the WTG is theoretically unable to provide any power surges during frequency events; however, it is possible to overload the WTG by a small percentage (e.g. 10\%) for a very short duration (from a few seconds up to 1 minute). This overloading was applied through the reduction of pitch angle. The same paper dealt with a critical problem which is the reaction of WTG when WS drops while the frequency support algorithm is executed. It presents the extraction of $\mathrm{KE}$ as a solution when WS shifts from high or moderate to lower ranges. The parameters of the algorithm are tuned through a certain algorithm according to the average WS at the WTG location. The major drawback of the proposed algorithm was its need for continuous WS measurements of an average precision. The method of evaluating $\omega_{\text {stop }}$ was not valid at all WSs due to the nature of the output power- $\omega$ curve of the WTG. Higher focus was directed on isolated weak power systems with high wind penetration and its coordination with diesel generators [47]. In this case, the torque reference was set to maintain a certain reserve examining both Delta and Balanced concepts. The auxiliary controller was provided by a RoCoF-input and frequency drop-input loops to tackle serious frequency events, and slower frequency changes respectively. 


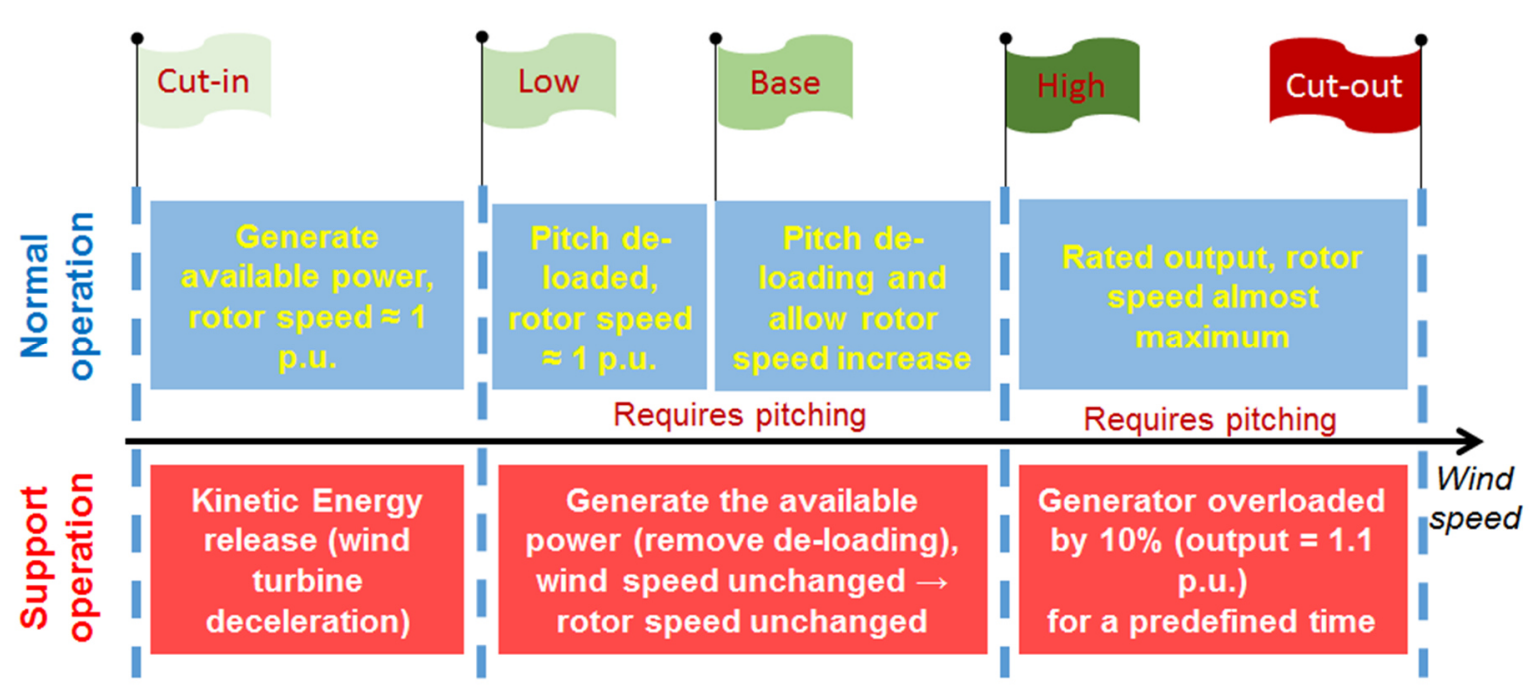

Figure 11 Partial de-loading method - operation regions and modes.

The impact of WS fluctuations during frequency events was also addressed in [43], where a typical droop function similar to approach followed in [48], to assign the WTG reference power. The droop value was not fixed but dynamic, so that the droop was linearly changing with WS (i.e. maximum droop at lowest WS, namely $6 \%$ at $5 \mathrm{~m} / \mathrm{s}$ ). The main concept was to provide the highest possible primary frequency contribution through minimizing droop value, and acknowledge the dynamic conditions of the WTG (mainly affected by incident WS).

The idea of WS categorization and setting different methods for frequency support was also presented in [48]. The procedure was based on setting a command power signal $\left(\mathrm{P}_{\mathrm{cmd}}\right)$, which was then divided by the actual rotor speed to provide the mechanical reference torque signal to the rotor current regulator. At low WSs, $\mathrm{P}_{\mathrm{cmd}}$ followed a linear relation as in (4),

$$
\begin{aligned}
& P_{c m d}=\text { reference output power }+ \text { slope } \cdot\left(\omega-\omega_{\text {reference }}\right) \\
& \text { slope }=\frac{\text { reference output power }-P_{\text {start }}}{\left(\omega_{\text {reference }}-\omega_{\text {start }}\right)}
\end{aligned}
$$

where $P_{\text {start }}$ and $\omega_{\text {start }}$ are the WTG output and rotor speed at a certain predefined low WS, typically just above the cut-in WS. This concept is almost similar to the idea proposed by Meng in [49]. At moderate WSs, no specific method to provide $\mathrm{P}_{\mathrm{cmd}}$ but it is stated that the WTG decelerates to achieve the torque balance according to the adjustable $\mathrm{P}_{\mathrm{cmd}}$. At high WSs, no power surge is available (i.e., the WTG is generating 1 p.u.), however, the authors tried to stabilize the WTG output by maintaining $\omega$ fixed to an upper limit. The model of the integrated pitch controller was relatively simple and received only the error in $\omega$ thereupon it was 
processed through a proportional controller (suggested gain from 3 to 10). Generally, frequency events made $\mathrm{P}_{\mathrm{cmd}}$ increase (or decrease when frequency rises) by a value determined using a typical droop function. The dependence on WS measurement is still one of the main challenges of this algorithm.

As a summary, the proposed concepts divide into two groups; the first one makes the support provided dependent on frequency deviation severity [45] [48], while the second approach secures a power surge that is independent from the frequency excursion as soon as the frequency violates the safe margin $[24,43,46]$. The stepwise techniques provide the power surge for a predetermined duration and/or till the minimum rotor speed is reached. However, stepwise techniques abruptly decrease the output after the predefined time to restore the rotor speed. The sudden power reduction might cause a second frequency dip. Therefore, the idea of predetermined or dynamic shaping of the active power support functions is introduced to mitigate the expected power abrupt drop prior to the support stage [33, 35, 50].

The majority of papers dealt with a fixed WS in each case study and ignored the possibility of the WS decreasing during support provision. Moreover, at normal operation, the WTG is controlled in Delta or Balance de-loading independent of frequency conditions. The idea of variable de-loading factors, which could be decided according to WS conditions or grid demand, was rarely investigated. The drawbacks caused by WS measurements were avoided in some papers (for example [45]) by utilizing the rotor speed as an indicator for the incident WS.

\section{Comparison of support methods}

This section provides a comparison between the different control methods presented in the previous sections. Such comparison concerns only with the impact of wind power contribution in frequency support.

The majority of papers compare the impact of inertia and primary responses on different real and hypothetical test systems. The test system always suffers a frequency dip, and then the frequency responses are compared in different case studies, namely; with zero wind power penetration, positive penetration-without frequency support, and positive penetration-with different types of frequency support. The comparison between frequency responses focuses on four main factors: frequency nadir, frequency deviation after a critical duration (i.e., $4 \sim 7 \mathrm{~s}$ ), oscillatory nature of frequency (i.e., Root Mean Square of oscillations; $\Delta f_{\mathrm{RMS}}$ ), and time 
required to stabilization within the safe margin that is typically around \pm 0.0015 per unit from nominal frequency $[46,51]$.

The comparison splits into two categories; the first one highlights the island systems [39, 52], and the other considers two large systems, which were investigated in two different papers [51, 53]. The penetration levels of wind power (in the four test systems) either in generation capacity or load coverage are mentioned in Table 1. Two different real island systems were integrated as benchmark systems to investigate the impacts of inertial and primary responses; Rhodes, Greece, and the Guadeloupe archipelago in [24, 51], respectively. On the other hand, the Western and Eastern U.S. Interconnectors are considered in [50, 52], respectively.

The two papers discussing island systems focused on the impact of inertial and droop gains so that several values of both gains are compared through assessing their impact on frequency recovery. The impact of different inertial gains in both systems is depicted in Figure 12. Note that the penetration level examined in Rhodes Island was lower and it had also achieved lower improvements in the nadir (e.g. at an inertial gain of 25; improvement was $0.43 \mathrm{~Hz}$ compared to $0.75 \mathrm{~Hz}$ in Guadeloupe system). Conversely, the discriminations between the power surges provided by the WFs in both systems at the beginning of the frequency event were not very high as shown in Figure 13.

Table 1 Investigated test systems in the selected papers.

\begin{tabular}{|c|c|c|c|c|}
\hline \multirow{2}{*}{ Test system } & \multicolumn{2}{|c|}{ Wind power penetration } & Loss of & Type of WTG \\
\cline { 2 - 4 } & in capacity & in load feed & generation & \\
\hline Rhodes [39] & $46 \%$ & $50 \%$ & $13.85 \%$ & DFIG \\
\hline Guadeloupe [52] & $29 \%$ & $18 \%$ & $12.75 \%$ & $\begin{array}{c}\text { Variable speed } \\
\text { (not specified) }\end{array}$ \\
\hline US Western Interconnector [51] & $54 \%$ & $50 \%$ & $1.40 \%$ & $\begin{array}{c}\text { Compared } \\
\text { Types 1 to 4 }\end{array}$ \\
\hline US Eastern Interconnector [53] & $5 \%$ & $18 \%$ & $0.14 \%$ & DFIG \\
\hline
\end{tabular}




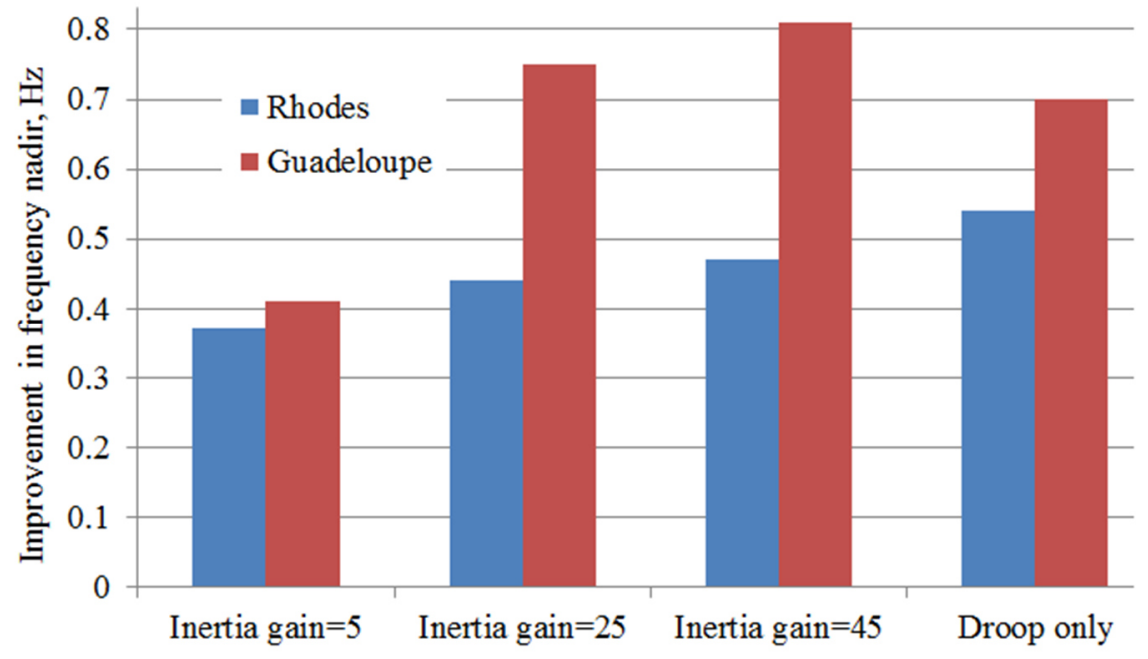

Figure 12 Improvement in $\Delta \mathbf{f}_{\max }$ in the two island systems for different inertial gains (Hint: de-loading in both benchmarks is $10 \%$, droop values in Rhodes and Guadeloupe were 20 and 25 respectively).

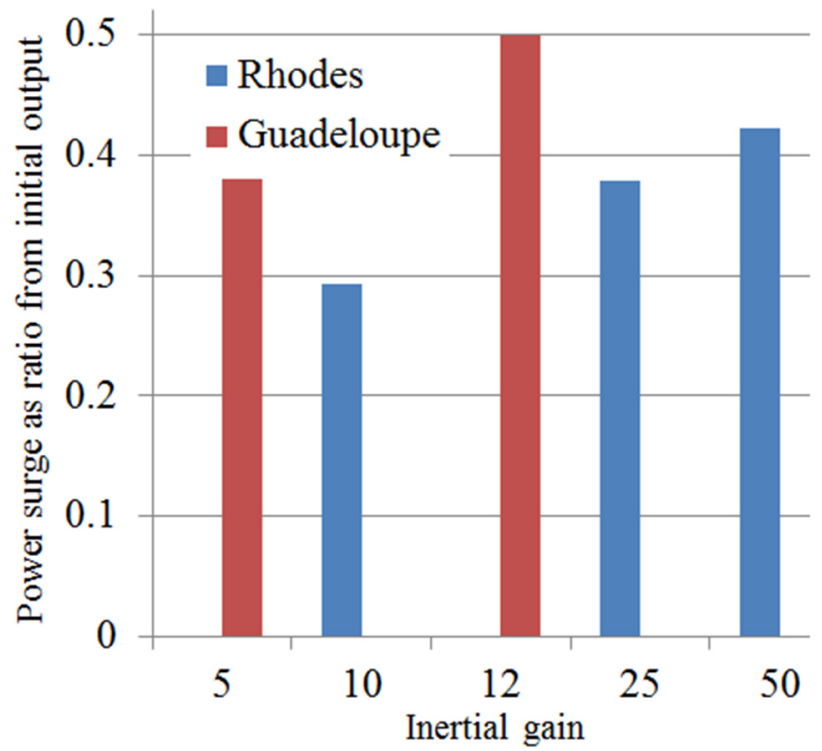

Figure 13 Supportive active power provided by WFs (Hint: simulations in the two papers were not conducted at the same inertial gain values).

On the other hand, the nadir improvements in large U.S. interconnections were largely mitigated as illustrated by Figure 14-a. The improvements in Eastern Interconnector were almost negligible due to the huge conventional generation capacity and the very low penetration of wind power. There was no data provided about the droop gain value and the deloading ratio in the Eastern Interconnection. Compared to island systems, the power surges provided by certain WF in the Eastern Interconnector were very low as shown in Figure 14-b. The inertial response, in the Western Interconnection, delayed the nadir by 17 seconds, but its magnitude was unchanged. Moreover, the overall droop response of the grid increased from 1544 to $4908 \mathrm{MW} / \mathrm{Hz}$ when the inertial and primary response support algorithms were activated for the WFs at $50 \%$ penetration. 
Wang et al. compared between Delta and Balance de-loading techniques (proportional and constant curtailment, respectively as in the cited reference) from the viewpoint of the secured primary reserve [54]. The energy efficiencies of the curtailed power through fixed short time spans were estimated using (5),

$$
\begin{aligned}
& \text { Energy effciency }=1-\frac{M W h_{\text {curtailed-unused }}}{M W h_{\text {curtailed-total }}} \\
& M W h_{\text {curtailed }, \text { unsed }}=\int_{0}^{T}(\text { Curtailed power }(t)-\text { Min. curtailed power during } T) d t
\end{aligned}
$$

where $\mathrm{T}$ is a certain time span, and $\mathrm{MWh}_{\text {curtailed-total }}$ and $\mathrm{MWh}_{\text {curtailed-unused }}$ are the curtailed total and unused amounts of energy respectively. The minimum amount of WF available curtailed power is considered as the secure reserve provided by the WF. This means that each WF will provide the short-term forecasts of expected generation and the minimum primary reserve to the system operator(s). However, WS fluctuations make the actual curtailed power higher than the aimed minimum reserve leading to energy wasting. The test system was the same as in [52], and the time span was 15 minutes, de-loading of $10 \%$ or $5 \%$ of rated power in the Delta and Balance methods, respectively. The Delta approach provided 10\% higher primary reserve, while the Balance approach provided reserve during $27 \%$ of the operation time. Another recent comparison touched on the impact of proportional integral gains of two supplementary controllers to provide pitch de-loading and virtual inertia (i.e. set-point for WTG output) [55]. The study presented root-loci and time simulations for wide ranges of the controllers' gains (pitching, torque and frequency droop WTG controllers) to investigate whether the system stability was aligned with the improved performance of frequency response. The study was conducted at different WSs and up to $50 \%$ wind power penetration into the installed generation capacity. The authors proposed new values for the gains and time constants of the WINDINERTIA controller based on their benchmark system and implied frequency event. The most important numerical values, recommended by this paper are as follows: the proportional gain of the pitch controller $=450$, the frequency droop of the proportional controller $=60$, proportional and integral gains of the torque controller $=3$ and 0.6, and WINDINERTIA proportional gain $=25$.

A general comparison between wind power frequency support methods is provided in Table 2 and illustrated in Figure 15. The following points are considered:

- Energy wasting is compared to MPT

- Response speed does not consider communication delays 
- Dependability on WS, namely during the event

- Support time/event is the continuous time of sustainable active power surge

Table 2 Global comparison between the main aspects of frequency support provision by wind power Red font refers to disadvantages, black; moderate characteristic compared to other methods, and green; clear advantage.

\begin{tabular}{|c|c|c|c|c|}
\hline Support Method & $\begin{array}{l}\text { Declarative } \\
\text { KE extraction }\end{array}$ & Over-speeding & $\begin{array}{l}\text { Balance de- } \\
\text { loading }\end{array}$ & Delta de-loading \\
\hline Energy wasting & Low & Higher & Highest & Higher \\
\hline Response speed & Fast & Faster & $\begin{array}{l}\text { Slower (pitching } \\
\text { response) }\end{array}$ & $\begin{array}{l}\text { Slower (pitching } \\
\text { response) }\end{array}$ \\
\hline Control complexity & Average & Higher & Higher & Higher \\
\hline $\begin{array}{l}\text { Secured primary } \\
\text { reserve }\end{array}$ & Lowest & Low & Highest & High \\
\hline Dependability on WS & Higher & Higher & High & Higher \\
\hline $\begin{array}{l}\text { Long/short term } \\
\text { solution }\end{array}$ & \multicolumn{2}{|c|}{ Shortest } & \multicolumn{2}{|c|}{ Short } \\
\hline Applicability & \multicolumn{2}{|c|}{ Variable speed WTGs only } & \multicolumn{2}{|c|}{$\begin{array}{l}\text { All WTGs (fixed speed types must be } \\
\text { equipped with pitching system) }\end{array}$} \\
\hline Support time/event & Shortest & Short & \multicolumn{2}{|c|}{ Long } \\
\hline $\begin{array}{l}\text { Possibility to support } \\
\text { consecutive events }\end{array}$ & Lowest & Lower & Average & Low \\
\hline Capital costs & \multicolumn{4}{|c|}{ Cost of controllers and software modifications-Low } \\
\hline Reliability & \multicolumn{4}{|c|}{$\begin{array}{l}\text { Increases failure rates of controllers and pitching systems } \\
\text { Accurate wind speed measurement might be required }\end{array}$} \\
\hline
\end{tabular}

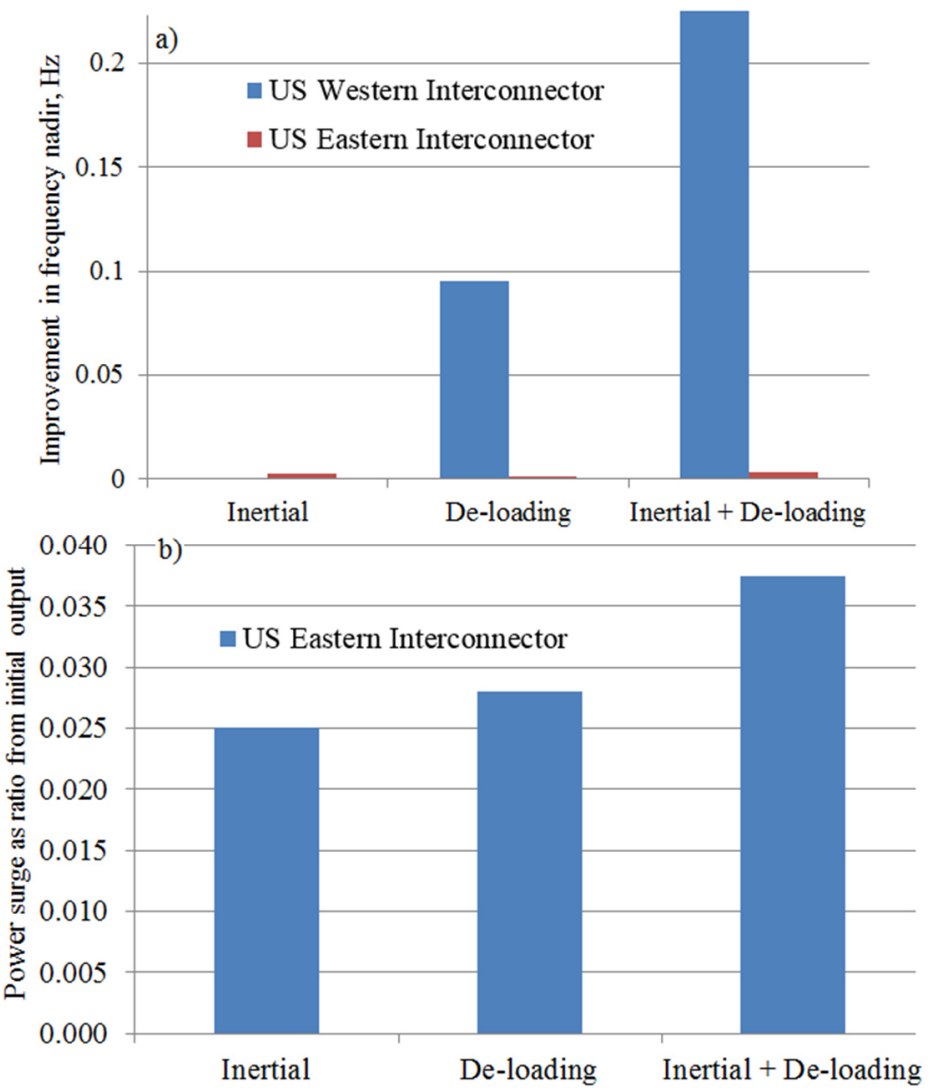

Figure 14 Improvement in $\Delta \mathbf{f}_{\max }$ and supportive active power in the two grids at different support methods (Hint: deloading in Western Interconnector was 5\% with droop gain of 25) 


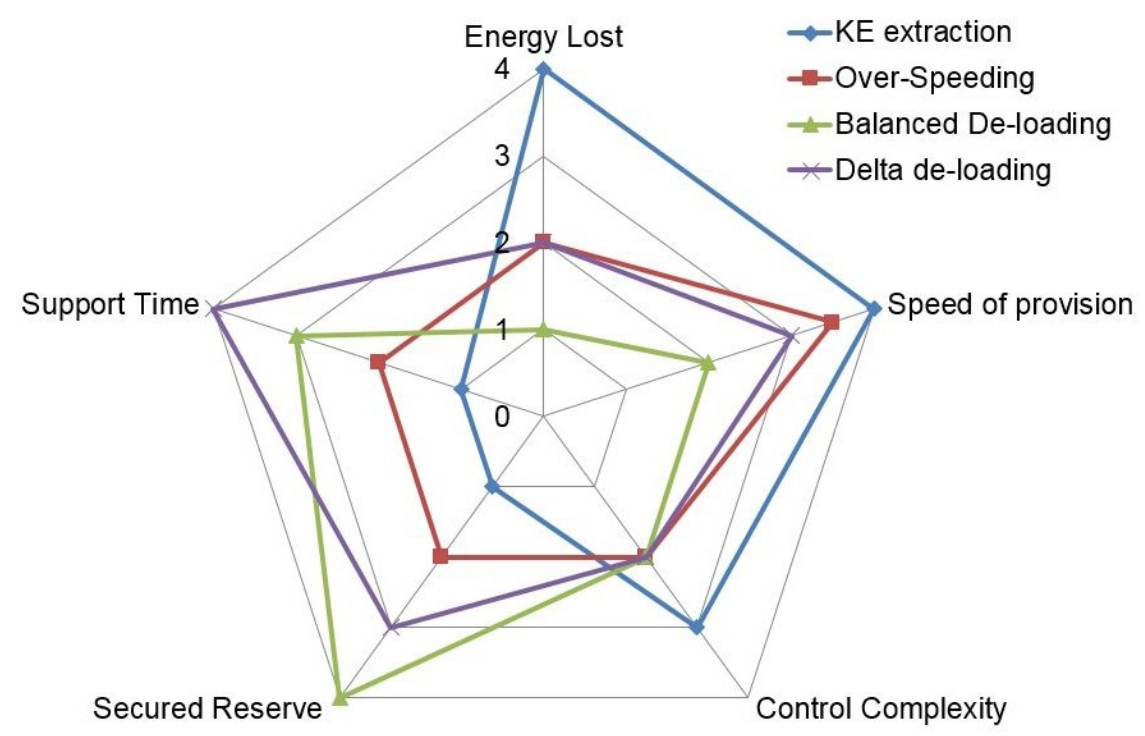

Figure 15 Spider graph comparing between the dominant frequency support methods

\section{Dispatching WTGs/WFs during frequency events}

The role of each WTG during frequency events should be defined so that the WF behaves as a conventional plant. Additionally, it is not practical to deal with each WTG as a conventional plant as there are thousands of WTGs connected to the power system. Thus, it is preferable to determine the required contribution from specific WFs according to the frequency deviation. Thereupon, a WF level controller decides which WTGs are switched to frequency support operation mode. This auxiliary controller should acknowledge the dynamic conditions of each WTG. The dispatching process assures that frequency recovery is smooth, avoids further drops, and improves the WF ability to support a second consecutive drop. There are two levels of dispatching, namely, dispatching WFs to determine the required contribution of each WF in the supportive power surge, and dispatching WTGs inside a WF to provide the WF share in power surge. The first level might be independent of the WF actual production, but counts on frequency event severity and the available conventional reserves. However, the second level completely depends on the actual conditions of each WTG inside the WF, then it is determined whether the WF is able to provide its share or not. A simplified WTGs dispatching criterion was presented in [23], where the incident WS on the WTG decided its share in the commanded power of the WF using (6),

Dispatching factor $r_{i}=\frac{\text { Weighting factor of the incident WS at } \mathrm{WTG}_{i}}{\sum_{i=1}^{A} N_{i} \cdot \text { Weighting factor of WS incident on group } i}$ 
where $A$ is the number of WTGs in each WF, and $N_{i}$ is the number of WTGs in each group. It was assumed each group of WTGs experiences the same category of WS. The dispatching factor depended on the WS conditions at certain WTG compared to WSs at other WTGs inside the same WF. A fixed weighting factor was assigned to each level of WS (e.g., at $7<\mathrm{WS} \leq 8$, the weighting factor is 3 ). It was not mentioned how the commanded power to the WF is interpreted as a control signal to the WTGs.

A compact WTG/WF and WF/WFs dispatching method was offered in [56]. A PI controller was integrated to determine the power surge required from all WFs according to $\Delta \mathrm{f}$. Afterwards, the instantaneous production of each WF determined its share in the overall power surge (i.e. WF/WFs dispatching). This PI controller acted as a conventional governor for all the integrated WFs. On the WTG/WF dispatching level, each WF was divided into predefined clusters where a certain number of clusters should participate in frequency support. Several clustering approaches could be applied; one of them is the average WS. As an illustration, the WF was divided into rows of WTGs, and it was assumed that each row is facing the same WS. According to wake effects, the initial WS is the highest, and it drops as it propagates from one row to the next. The dispatching algorithm decided how many clusters were required to provide the commanded power surge from the WF. The clusters which faced higher WS were given the priority. It was also interesting to perform a preparatory study to assess the maximum possible power surge from each WF at a moderate WS. This process required the knowledge of the number of WTGs, their ratings and types, and the applied support algorithm (as discussed earlier in Sections 2 and 3). The concept of a frequency deviation dependent PI controller was also offered in [48], to adjust the command power to WF ( $\left.\mathrm{P}_{\mathrm{WF}-\mathrm{cmd}}\right)$. As an illustration, the WF was treated as a conventional plant however; the command signal was restricted by the WF production. The moving average method was implemented to estimate the available WF power through certain time interval T using (7),

$$
\begin{aligned}
& P_{W F-c m d}=\sum_{i=1}^{N}\left(P_{M . A}-\text { weighting factor } \cdot P_{d e v}\right)_{i} \\
& \left.P_{d e v}=\sqrt{\frac{1}{T} \cdot\left(\int_{t-T}^{t}\left(P_{W T G-M P T}-P_{\text {average }}\right)^{2}\right.} d t\right) \\
& P_{\text {average }}=\frac{1}{T} \cdot \int_{t-T}^{t} P_{W T G-M P T} d t
\end{aligned}
$$

where $P_{M A}$ is the moving average of the WTG output at MPT, and $P_{d e v}$ is the deviation of WTG output from its available (i.e. MPT). A higher value of weighting factor gave the WF higher 
confidence to provide frequency support, but increased sacrifice in wind energy production. When a frequency event occurs, most probably the limit of $P_{W F-c m d}$ is violated and the WTGs must switch to frequency support mode to provide the required power surge. All the WTGs were switched to frequency support mode at the same time. Thus, [48] merged the concept of WF clustering [56] and setting power reference of both WF and each WTG [23].

Baccino et al. deviated from the classical PI controller applied in [48] [56], and proposed a central controller equipped with a Kalman filter which was responsible for setting the reference speed and power for each WF, meanwhile a local filter did the same task for each WTG within the WFs [57]. The Kalman filter estimated the external load variations through receiving WF aggregate output and $\Delta \mathrm{f}$ signal at the point of connection of the WF to the grid. These load variations were then fed into a central predictive model controller. The central controller played a novel role as it integrated between load variations and dynamic conditions of each WTG inside the WF, as shown in Figure 16. The dynamic data of each WTG (incident WS, $\omega, \beta$ ) was refined using the local Kalman filter. When frequency events occurred, every WTG responded differently according to its dynamic conditions and the central controller provided an additive control signal for each WTG which determined the frame of the supportive action from each WTG (i.e. for WTG no. $i$ : $\mathrm{P}_{i \text {-ref }}=\mathrm{P}_{i \text {-local control ref }}+\mathrm{P}_{i \text {-central controller signal). The central predictive }}$ model controller performed an optimization process within each time frame to maintain the WTG's operation within preset limits and mitigate $\Delta \mathrm{f}$ taking into consideration the WTG's dynamic conditions. A central controller was also implemented in [58], to provide aggregate measurement information for the local controllers of WTGs and flywheels. In particular, the central controller received the penetration power margin for both; the WF and the integrated storage (provided by SOs), the output of all WTGs at the point of connection with the network, the common rotational speed of the flywheels, and frequency deviation. The central controller provided local WTGs governors with the power deficit to be stored or extracted to suppress frequency events. Thus, the WTG output power is ramped up or down using the local governor to preserve the pending conditions of the flywheels and the power system.

The issue of dispatching AC synchronized area(s) and wind power clusters connected via pointto point or mutli-terminal HVDC grid was raised in [59-61]. A local controller was integrated into each synchronous area to set the power surge provided either by conventional plants (in synchronized areas) or by WFs as shown in Figure 17 [59]. The proposed dispatching was more universal as it dispatched all the synchronous generators and WFs which are interfaced through power electronics of the HVDC. Two different controllers were proposed, one for each AC 
area and the other for the wind power cluster. The controllers were not so sophisticated, and their two main design parameters were tuned using an advanced optimization algorithm. On the other hand, the dispatching method was very simple based on a proportional, fixed gain, which was predetermined based on the penetration ratio of wind power in load feed. The impact of communication failures on the dispatching process was tackled by [59] where the power supplied from one of the AC areas was intentionally missed in a case study to examine the controllers' response. A solution for communication delays was to modify the magnitude of pulse width modulation signal, controlling the HVDC link converters, according to the onshore frequency (i.e. grid frequency) [60].

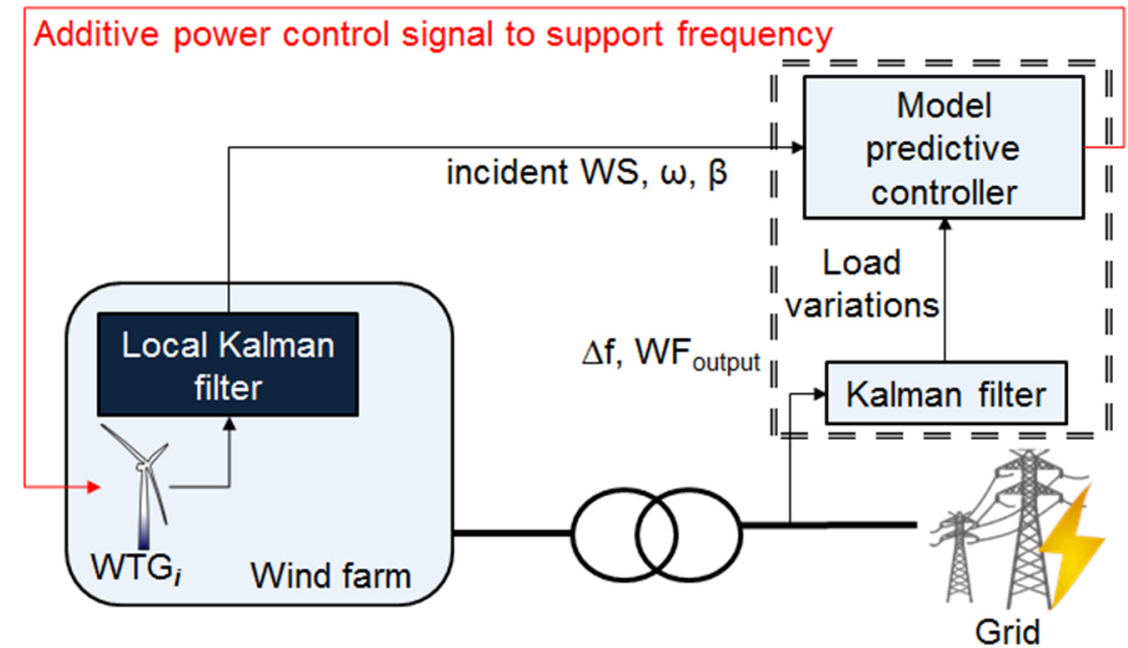

Figure 16 proposed WF dispatching controller in [57]

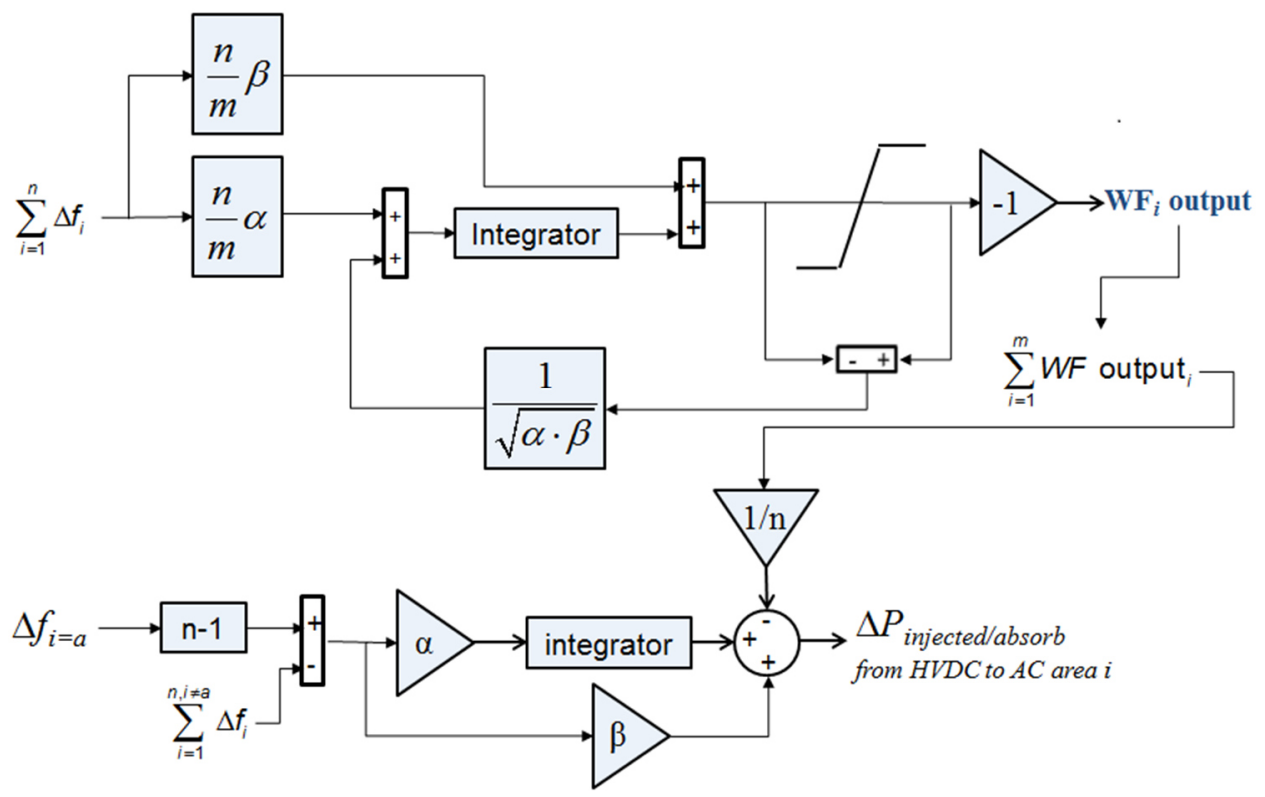

Figure 17 Coordinated control to provide frequency support from WFs and synchronous AC areas connected to a HVDC grid ( $\mathrm{n}$ and $\mathrm{m}$ are the numbers of $\mathrm{AC}$ grids and WFs respectively, $\alpha$ and $\beta$ are two design parameters) 
As seen, the common concept in the papers surveyed is the integration of a central controller (PI in most cases) to set the reference output of WF/WFs and WTG/WF or switch it to support mode. The available measured data were filtered in some research to enhance the dispatching process. The WTGs inside a WF were divided into groups or clusters according to weighting factors or other clustering parameters (e.g. WS). The proposed designs are feasible and ready to apply without the need for major equipment installation or considerable alternations

\section{Technical challenges}

This subsection presents the identified obstacles to be considered and solved to advance the participation of wind power in frequency support. It is worth noting that not all challenges are common to all support methods, and that one of the major obstacles is the presence of sufficiently reliable and fast data acquisition and communication systems. In addition, such wide cooperation between power systems and WFs requires a clear and well defined technical and legal rules and protocols to avoid any conflicts with other aspect of stability (e.g. small angle stability and its controllers) [62].

One key area related to wind power globally is the development or modification of balancing markets. These ancillary service markets were typically designed for the operation of conventional generation. Furthermore, the standardization and common regulation of such markets has been proposed to support growth in renewable penetration. It must be noted that economic, regulatory and market-related issues out with the scope of this paper.

\subsection{Wind speed measurement or estimation}

To determine or know the actual wind speed faced by the wind turbine is a prerequisite for several frequency support algorithms. However, the accuracy of the obtained measurements or prediction will always be questioned. The impact of error in wind speed estimation depends on the algorithm in question $[63,64]$. Some algorithms count on WS as a categorization or dispatching parameter. In other algorithms, such as MPT, incident WS plays a major role in setting de-loading ratio and determining the reference rotational speed and/or torque. One modern and promising WS measurement methods is the LIDAR (Light Detection And Ranging) [65]. Frequency measurement is also a much debated topic, for example, choosing where to locate frequency sensing equipment to trigger frequency support algorithms (e.g. at the point of common coupling or the collection bus of the WF, or it should be communicated through the SOs to WTGs/WFs controllers). Methods of frequency measurements are also 
widely discussed, where PLL is the most applicable method [66]. However, the topics related to frequency measurements are out of the scope of this paper.

\subsection{Action to be taken at non-sufficient WSs}

Generally, the most practical solution in case that wind speed drops during frequency support provision is to extract the stored KE in the rotating parts of the WTG to maintain the initially provided level of support. On this track, a quantitative study was conducted to estimate the future evolution of PR and system inertia in the GB power system (required to face a worst loss of generation of $1800 \mathrm{MW}$ ) for different policy scenarios [67]. The authors asserted that over-speeding techniques make the WTG contributes to the system inertia (i.e. the reduction of system overall inertia due to conventional generation retirement is mitigated) and PR while other support methods practically act as PR only. The performed case studies achieved very high penetration levels up to $50 \mathrm{GW}$ wind power/70GW load. The main finding was that as the load increases, the PR requirement was reduced while the increase in wind power penetration had a minor impact. However, when there WFs did not provide frequency support, as the penetration increased a slight variation in load caused major impact in PR requirements. Under this scenario, energy storage is a valid solution; however, it is still facing major economic barriers due to the high capital costs. Energy storage is also an alternative for replacing fixed speed WTGs with modern variable speed WTGs. Details of potential integration of energy storage for frequency support are given in the coming sections.

\subsection{Energy wasting (Energy loss)}

Wind energy is wasted either due to de-loading or during the recovery phase after providing the supportive power. The amount of wasted energy is always compared with respect to the available energy when the WTG is operated using MPT. A detailed comparison between wasted energy in three major support techniques is found in [26]. In particular, wasting energy is an economical problem which affects WF owner/operators as they may have to sacrifice energy to assure the capability of their WF to provide frequency support. However, developing support algorithms can mitigate the wasted energy to facilitate the compromise between grid requirements and investors' targets. In addition, future grid codes should include special incentives for the WFs which will participate in frequency support as a compensation for the expected curtailment in energy production. Compared to the previous obstacle, energy storage is a valid solution to eliminate any energy wasting; on the contrary, it may improve the energy 
yield of WFs by storing wind power which might otherwise be curtailed during period of low demand.

\subsection{Universal and standard solutions}

Providing generic and common options for the appropriate selection of the support algorithm are a priority. To date, there is no accredited procedure through which system operators and WF owners can decide which support algorithm is best suited to their needs. The complicity of the challenge relies on the wide range of givens, parameters and requirements that should be considered and compromised as illustrated in Figure 18. A complicated mesh of different issues makes it very hard to provide a universal criterion or set of equations to determine the suitable replacement ratio for conventional plants with WFs, and the best frequency support algorithm. In addition, the comparisons in the previous section show that the impacts of support algorithms vary significantly between large grids and isolated systems. Moreover, the capacity factor of WFs may vary from around $20 \%$ up to $55 \%$ depending on location [68]. It is also challenging to decide whether all the WFs should contribute to frequency support, as from an economic point of view this is not effective. The infrastructure of the system has a big influence, for example, the speed and accuracy of communication devices between different plants (i.e. WFs dispatching is highly affected by the speed and accuracy of data acquisition) [69]. A novel study was undertaken in [67] to estimate the required primary reserve post high penetration levels of renewable energies in GB in 2020 (Go Green scenario). A generalized probabilistic method was also applied to the Go Green scenario to estimate the available inertial response provided by wind power and its impact on system. The weighting factor of each WS block was related to the installed wind capacity in each region and probability of ramping between two WS classes. This weighting factor was then multiplied by the estimated inertial response from the WFs assigned to each block (applying the method of [34]). It was found that, at $1.8 \mathrm{GW}$ generation loss, the frequency nadir and RoCoF of highest occurrence probability were improved by $0.1 \mathrm{~Hz}$ and $0.08 \mathrm{~Hz} / \mathrm{s}$, respectively.

The generalization of frequency stability risk assessment was touched by Negnevitsky et al. in their recent paper [70]. They proposed a simplified risk assessment approach to analyse the system operation under high penetration of wind power by the identification of operational limit through an analytical solution (using Laplace transforms) that approximates dynamic response in frequency domain. This method allows droop frequency response to be modelled as a linear ramp response. The amount of non-supplied energy are estimated according to 
expected load curtailments (i.e. based on the obtained frequency response) and financial losses and adequacy issues are quantified. Similar work was conducted to estimate the system inertia and primary reserve of wind power plants through a simplified mathematical representation of power system [71]. In spite of the intensive research efforts there is still no standard or widely applied methods that enable the WTG to provide frequency support. However, top WTG manufacturers, including Vestas and Siemens, had patented practical approaches that are compatible with their WTGs. Most of the patented methods are based on de-loading concepts $[72,73]$.

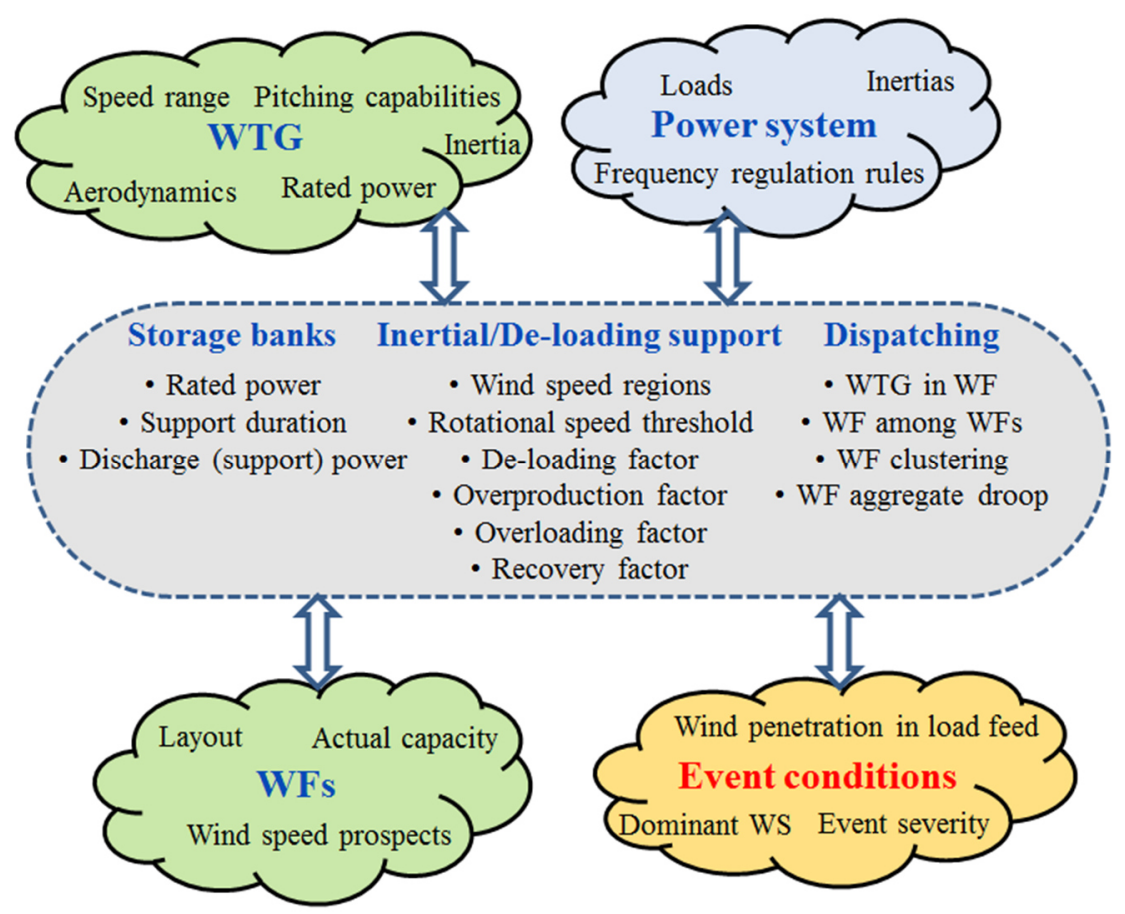

Figure 18 Illustration for the 'Generalization' dilemma

\subsection{Frequency dead-band}

This case defines the region where WFs/WTGs do not contribute to frequency support. The operation region of the applied support algorithm is decided based on SOs requirements depending on frequency deviations. However, the width of this band depends on the wind power penetration level, and the targeted contribution of wind power to frequency support (i.e. full response; inertial, primary and secondary). It is most common to instruct WFs to react to moderate frequency drops by providing inertial and primary responses with a frequency deviation deadband of $\pm 0.1 \%$ and $\pm 2.2 \%$ minimum and maximum thresholds respectively [13, 74]. 


\subsection{Suitable de-loading ratio}

The selection of this parameter is related to many factors including the WTG rating, average WS in the location, grid code requirements, and method of de-loading. In addition, de-loading would have a clear impact on the capacity factor of a WF if not corrected for. For example, applying $10 \%$ de-loading reduces the capacity factor by $3 \%$ in an example from [43]. However, a sufficient de-loading ratio should achieve a reasonable value of the power surge, which is determined by SOs. A de-loading ratio of $15 \%$ was applied in [46] to reach a 0.15 p.u. power surge at average WS. Moreover, the de-loading ratio could be assessed for the whole WF, such that the WF is treated as a power plant with an expected primary response. In that case, a WTG dispatching algorithm may be applied to achieve variable de-loading for individual WTGs so that the aggregate supportive power fulfils the WF target droop [56]. This point and the previous one are closely related to grid code requirements which differ from one country/region to another. The dominant trend does not obligate the WTGs/WFs to provide inertial or primary response [75]. However, WFs must reduce their production (e.g. Germany; a ramp rate 10\% of connection capacity/minute) during the intervals of low demand to avoid positive frequency deviations and to maintain the allowed penetration levels in feeding the actual load [76] [77]. On the other hand, some codes treat medium sized WFs a power plant so that they expect the frequency response at the point of common coupling follows the grid code and the WTGs have to provide a power surge within the limits of the code according to certain agreement with SOs. This type of operation is closely related to the financial impact on the WFs owners and in most cases SOs offer additional incentives for WFs to provide frequency support. However, this aspect is out of the scope of this paper, but has been be reviewed in [78].

\subsection{Equipment's reliability}

The reliability of the wind turbine is affected by the operation algorithm of WTGs. In wind power, reliability is a critical issue as it is very costly, hard and dangerous to have access to the WTGs components which are mounted atop high towers. In addition, massive amounts of potential energy capture are lost due to both planned and unplanned maintenance [79]. Therefore, frequency support algorithms should have limited negative influence on component reliability. For example, pitch de-loading implies additional stress on the mechanical pitching system so that it is more vulnerable to failures. Likewise, intensive rotational speed control affects the lifetime of WTG low speed shaft and gearbox and even the tower base [80, 81]. The 
overloading technique offered in some algorithms in case of rated WS operation could reduce the lifetime of the machine insulation and increase the risk of winding failure.

\subsection{The layout and the type of connection}

The collection grid and the power transmission system have an impact on a wind farm's ability to provide frequency support. The interconnections between WTGs inside a WF might be AC, DC or hybrid. Likewise, a WF, especially offshore WFs, could be connected through an HVDC corridor [79]. In case of HVDC connections the power surge provided by the WF is limited by the power ratings and the rate of change of the delivered power of the connection converters. Moreover, the WF senses frequency deviation as the point of coupling with HVDC line or at the point of coupling of HVDC (i.e. inverter end) with the grid. However, future modifications to grid codes should clarify which frequency measurement is acknowledged to trigger a given support algorithm. The speed of response should be also examined to compare between conventional AC lines and HVDC corridors. This point has been widely addressed in [82]. Table 3 concludes the eight key obstacles in the way of wide and complete dependence on wind power as a robust participant in frequency support. The impact of the two last challenges and the proposed solutions are introduced in Section 4

Table 3 Major technical obstacles facing wind energy participation in frequency support Numbers below each challenge refer to the involvement of support techniques in the evolution of the challenge (1: synthetic inertia techniques, 2: de-loading techniques and 3: energy storage)

\begin{tabular}{|c|c|c|c|}
\hline Challenge & System operators & Owners & Manufacturers \\
\hline $\begin{array}{c}\text { Wind speed measurement } \\
\mathbf{1 , 2}\end{array}$ & & & $\checkmark$ \\
\hline $\begin{array}{c}\text { Action at non-sufficient WS } \\
\mathbf{1 , 2}\end{array}$ & & & $\checkmark$ \\
\hline $\begin{array}{c}\text { Energy wasting } \\
\mathbf{1 , 2}\end{array}$ & $\checkmark$ & $\checkmark$ & $\checkmark$ \\
\hline $\begin{array}{c}\text { Universal solutions } \\
\mathbf{1 , 2 , 3}\end{array}$ & $\checkmark$ & & $\checkmark$ \\
\hline $\begin{array}{c}\text { Frequency dead-band } \\
\mathbf{1 , 2 , 3} \\
\end{array}$ & $\checkmark$ & $\checkmark$ & \\
\hline Suitable de-loading ratio & & & \\
\hline
\end{tabular}




\begin{tabular}{|c|c|c|c|}
$\mathbf{2}$ & $\checkmark$ & & $\checkmark$ \\
\hline Equipment's reliability & & & $\checkmark$ \\
\hline $\mathbf{1 , 2}$ & & $\checkmark$ & \\
\hline Type of connection to grid & $\checkmark$ & \\
\hline None & & $\checkmark$ & \\
\hline
\end{tabular}

\section{Frequency support via stored wind energy}

The previous methods of frequency support count only on the available wind power just before, during and shortly after the frequency event. Therefore, these methods are vulnerable to WS variations and their potential contribution to frequency support in the near future is uncertain. In addition, the WTG may operate below MPT for extended periods of time, which would imply a negative economic impact on the WF revenues if no additional remuneration was available for providing frequency support. To overcome these obstacles, supportive power surges might be fully generated or shared by more stable and highly predictable source of energy to alleviate the incident frequency event. Literature had investigated several types of energy storage mediums, some of them are still in early stage of research and prototyping, and others stand on a solid ground of mature technologies [83]. This paper has considered three means of energy storage that are widely deployed in power systems and intensively examined in literature, namely, batteries' banks (BBs), hydro-pumped energy storage (HPES) and flywheels (fw). The research efforts on the role of these three storage mediums in providing short term frequency support are rare. Thus, this paper discusses the trademark contributions in the field of energy storage participation in balancing wind power (i.e. mitigating small deviations), and how they might be utilized to provide frequency support services.

\subsection{Batteries' banks}

The majority of research concentrates on the role of BBs in flattening the output of WFs to overcome WS intermittency. The impact of BBs on system frequency deviations was examined in [84], where the penetration level in generation capacity was limited by certain threshold for frequency deviations. Exhaustive mathematical analysis was presented and full interest was directed to frequency support. In addition, BBs sizing was based on statistical and historical data not the accuracy of wind power production forecasts. A complicated mathematical method was applied to convert the available real WS data into equal time-sized samples of wind power, where each sample has its own average and static stochastic fluctuations reflecting wind turbulence. Thereupon, wind power is integrated into a detailed model for the examined system so that the frequency is obtained through the complete time interval (i.e. several samples). The 
penetration level was then monitored and increased until the frequency deviation threshold is violated. The next step was integrating a storage medium to improve the frequency response of the system. A novel idea assumed that the BB acts as a band-stop filter, where it should avoid the frequency deviations which had a certain rate of occurrence. The performance of this filter in time domain should follow the behaviour of frequency deviations (which is based on the stochastic wind power fluctuations as mentioned earlier). $\Delta \mathrm{f}$ with the lowest occurrence rate are always the highest, thus higher surge power is required to suppress it, hence these records were excluded. The final size of the BB was compromised with the stopped bandwidth taking into consideration the efficiencies of charging and discharging, and preserving a maximum limit for $\Delta \mathrm{f}$. As an illustration, each time sample required a different sized BB (according to wind power variations and frequency deviations), but only one size is selected (i.e. rated power and energy capacity). The optimum upper and lower limits of SOC were acknowledged in each time sample to maintain the normal range of BB lifetime.

A different approach was presented in [85], where the BB is overloaded for certain duration according to the permissible thresholds released by the manufacturer. A lookup table is integrated to determine the allowed overloading factor and duration at the instant of frequency drop and according to the $\mathrm{BB}$ accompanying conditions. The BB was modelled as voltage source inverter to handle sudden changes in frequency and voltage. As an illustration, SOC and $\Delta \mathrm{f}$ signals are processed through two independent PI controllers to set the reference value for the current d-component of the converters connecting the BB to the grid as shown in Figure 19. The BB charge-discharge process is performed during normal frequency conditions, but at frequency drops; overloading is triggered, however, reaching the SOC minimum limit of $20 \%$ should halt the support process. The concept of charging-discharging BBs according to frequency conditions and load demand was also investigated in [86]. The sizing of BBs was based on chronological data as in [84], however the size of BBs was selected to cover possible gaps between generation and demand, according to the available WSs records (to avoid frequency drops that arise due to imbalance). A similar concept was adopted in [82] where the power surge (i.e. rated power of the BBs) is tuned according to the corresponding primary reserve from the retired conventional plants. The rated energy was selected to secure a sustainable power surge of a 3-stage shaping function (Ramping inertial response, fixed primary response, and decaying to assure stable frequency recovery). The major novelty was expanding the optimization process to achieve a low total operating cost of conventional units and BBs (, without violating acceptable limits of RoCoF and frequency nadir. The deficiency 
of this work was its dependence on a very simplified equation describing the RoCoF variations according to the provided inertia by BBs. In addition, it was an event-dependent method, such that the severity of the generation-load mismatch decides the RoCoF hence the BBs size. Through all the previous papers, several types of batteries were implemented; however the most popular types in the field of rectifying and balancing the intermittency of renewable energy are NaS and Li-ion [87].

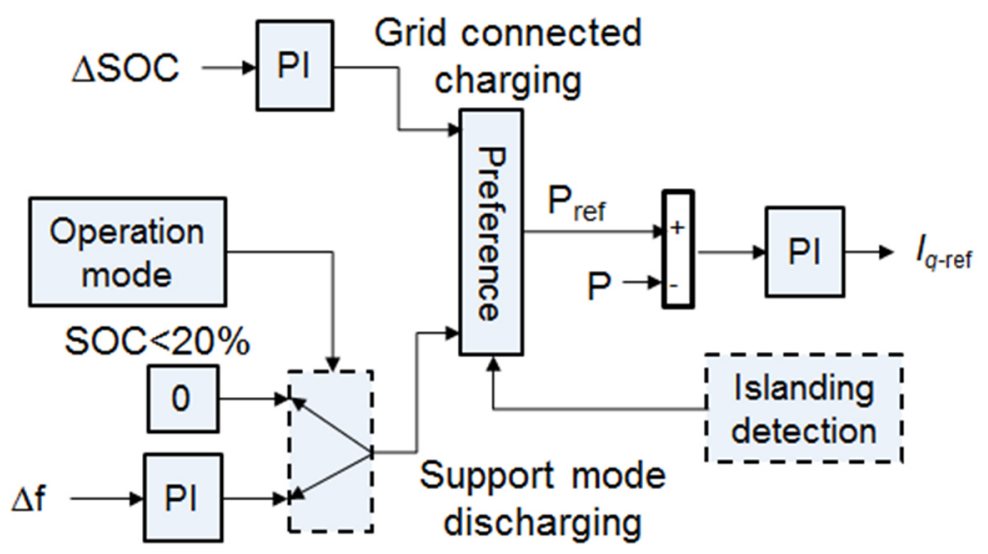

Figure 19 Charging-support algorithm offered in [85]

The energy stored in the dc capacitors of the PE converters and the capacity of the HVDC cables can be considered as a virtual battery that is able to provide frequency support. The benefits of combining this stored energy along with WFs frequency support were proposed in $[60,82]$ by integrating the appropriate ancillary controller as shown in Figure 20 [60]. Both papers compared three approaches to provide frequency support from WFs which are connected via HVDC links (namely, point-to-point); WTG-based, HVDC stored energy (where the dc link voltage drops below nominal to stored extract energy in the capacitors), and a combination between the two previous methods. The authors saw that the main obstacle for the first choice is communicating the frequency measurements to the WTG controllers. Meanwhile, the energy stored in HVDC link required to produce an inertia time comparable to a conventional plant is very high compared to the normal capacity of HVDC links (17 times more according to [82]). The combined method tackled the two problems where the initial voltage drop in HVDC provided the fast-enough response which is gradually supplemented by the WTG. The WF senses the HVDC voltage drop at the WF side converter to initiate the WTGs frequency support protocol (i.e. the droop response was proportional to the dc voltage drop). It was concluded that HVDC energy extraction is preferred when fast WTGs response is required; while WTG-based is favoured when the WTG should provide frequency support for relatively longer durations [82]. Both papers used DIgSILENT PowerFactory as a 
simulation environment, however the controllers' presentation and reproduction by the readers were simpler in [60], and it considered the behaviour at over-frequency events when the frequency violated the E.ON code margin, namely $50.2 \mathrm{~Hz}$ [88].

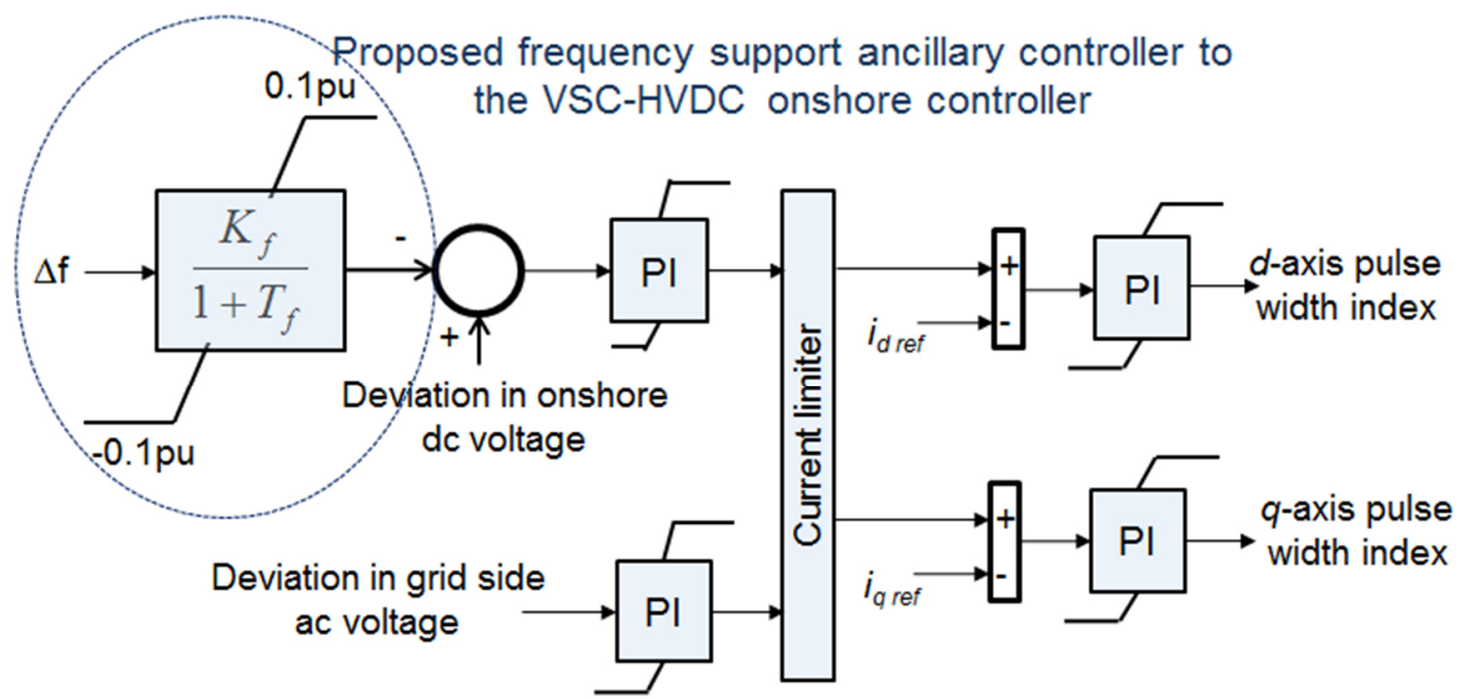

$\mathrm{K}_{\mathrm{f}}$ and $\mathrm{T}_{\mathrm{f}}$ are the gain and time constant of the proposed controller respectively

Figure 20 Ancillary controller integrated to VSC-HVDC onshore side to provide frequency support

\subsection{Hydro-pumped storage}

HPES represents $99 \%$ of the energy storage capacity installed all over the world [87]. A sizing algorithm was offered in [89], which depended on evaluating a chronological array for the generation-load mismatches through the whole year after specific WFs replaced some conventional units. The general structure of a HPES is displayed in Figure 21. The HPES was proposed to be constructed onshore of the Red Sea in Egypt without a lower reservoir, and the sizing procedure decided the volume and head of the upper reservoir. The energy capacity and rated power are compromised to guarantee a fixed support power for 30 minutes. The proposed sizing algorithm is so far similar to the one proposed in [86]. 


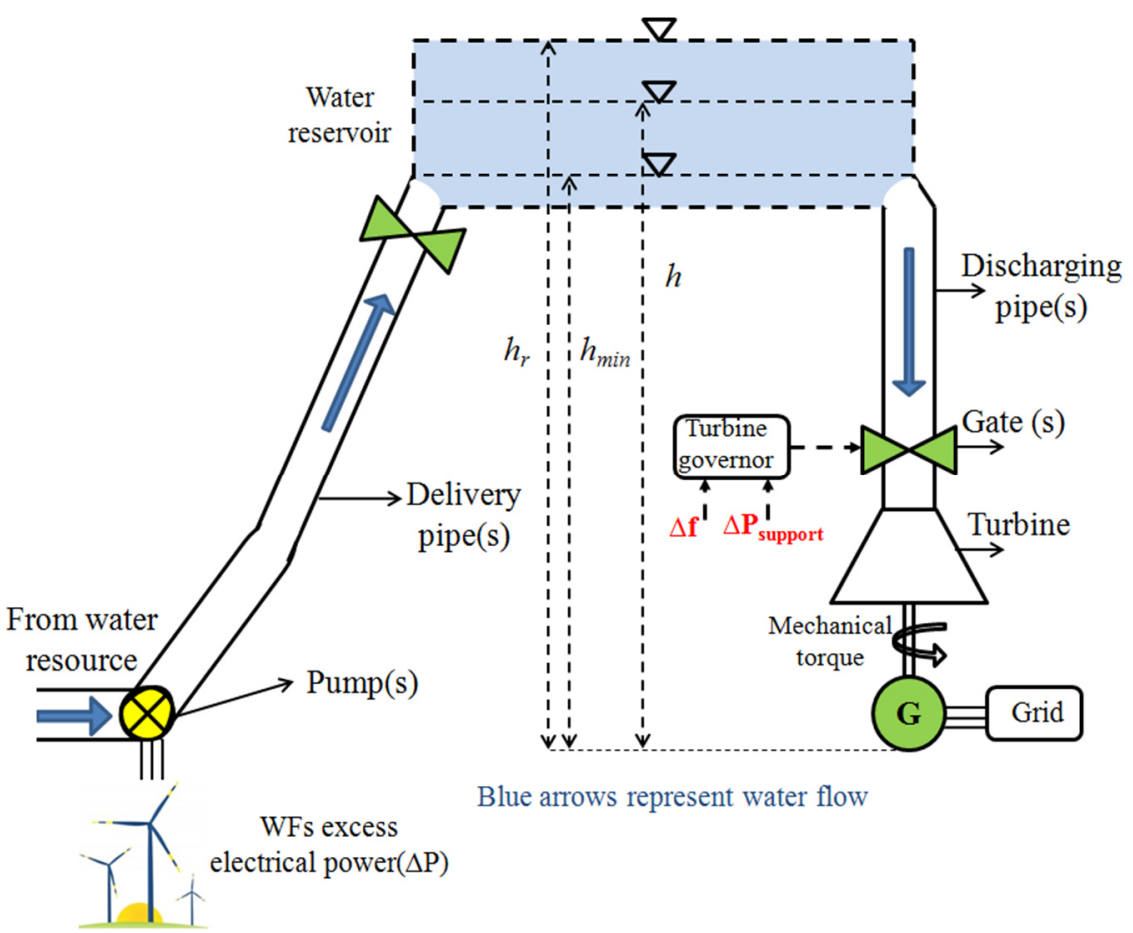

Figure 21 Typical structure of an HPES [89]

The rated power and flow rates of charging pumps were selected based on the power mismatch array. However, this study requires more sophisticated statistical, probabilistic approach, such as Monte Carlo simulation to get more accurate results. As an extension of this work, a detailed operation algorithm is presented in [90] to determine how the HPES was charged without causing frequency excursions, and also mitigating the rejected wind power. During frequency events, the HPES responded as a normal hydro plant with a simple mechanical governor, meanwhile the WTGs do not have any contribution to frequency support. It is of note that the head height was designed to be relatively short $(80 \sim 100 \mathrm{~m})$ to assure an ultrafast response in primary support. The HPES was considered as an additional inertia in the system which mitigated the lowered inertia after the WFs had replaced some conventional units.

\subsection{Flywheel energy storage}

Finally, the method of WTG de-loading and integrating flywheels as a storage medium was proposed in [58]. The basic source for frequency support was several flywheels integrated near a WF, and they exchange power with grid according to frequency fluctuations based on a linear control droop as shown in Figure 22. The available power from flywheels was estimated according to the stored KE so that a fixed power step is provided within 30 minutes (notice that 30 minutes support duration is common in literature) using (8), 
$P_{a b s o r b}=($ no. of flywheels $/ \Delta t) \cdot\left(J_{f w} \cdot\left(\omega^{2}-\omega_{f w-\max }{ }^{2}\right)-\right.$ Torque losses $\left.\left(\omega^{2}-\omega_{f w-\max }{ }^{2}\right) \cdot \Delta t\right)$

$P_{\text {inject }}=($ no. of flywheels $/ \Delta t) \cdot\left(J_{f w} \cdot\left(\omega^{2}-\omega_{f w-\min }{ }^{2}\right)-\right.$ Torque losses $\left.\left(\omega^{2}-\omega_{f w-\min }{ }^{2}\right) \cdot \Delta t\right)$

where $\omega_{\mathrm{fw}}$ is the flywheel speed, $\Delta \mathrm{t}$ is the frequency regulation duration, and $\mathrm{J}_{\mathrm{fw}}$ is the flywheel inertia (all flywheels are identical).

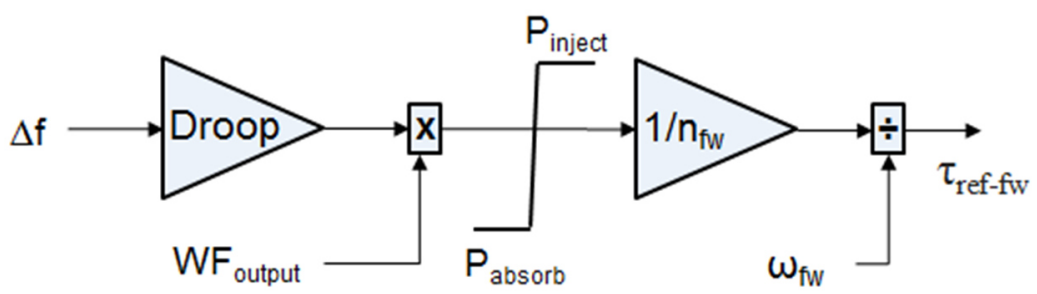

Absorb/Inject limits based on the rated power of the flywheel (fw)

Figure 22 Flywheels frequency support droop controller [58]

When the frequency suffers an overshoot, the term of minimum rotational speed is replaced by a max limit (the ability of flywheel to absorb more energy, hence it draws the excess power to mitigate the frequency rise). On the other hand, typical combined torque-pitch control was applied to maintain Delta de-loading for the implemented WTGs.

\subsection{Energy storage systems comparison}

A brief comparison between the three storage technologies gives an insight into the merits of each technology as shown in Figure 23. It is seen that the HPES has a slight privilege, however the main obstacles are the environment suitability and massive capital costs [16]

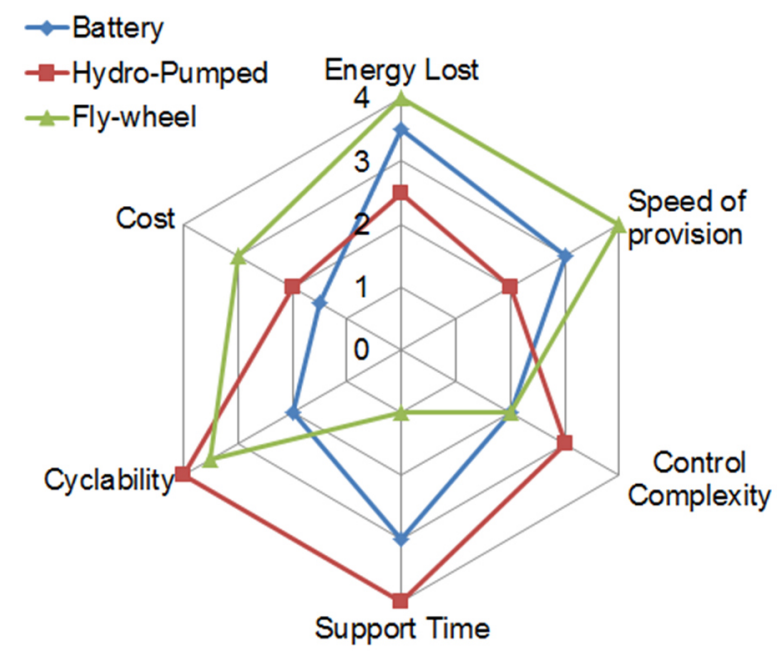

Figure 23 General comparison between the three main energy storage technologies 


\section{Conclusions}

The role of wind power in frequency support has been an active field of research for several years. A wide range of algorithms and investigations have been published to tackle the problem of reduced system inertia and primary response provision when wind farms replace conventional generators. The solutions offered are based on three methodologies; kinetic energy extraction, controllable de-loading, and integrating energy storage mediums. Hydropumped storage stations and batteries are the most widely used storage mediums worldwide. Although energy storage almost eliminates wind energy wasting compared to other methods of support, it has many financial and technical limitations.

Variable speed wind turbines are able to provide frequency support by via specially designed control algorithms. However, the dominant wind speed conditions before, during and just after the frequency excursion play a major role. The impact of providing support on frequency response depends on many factors, including the nature of the power system (i.e. large grid or island system), the drop severity and the parameters of support algorithms (e.g. inertial and droop gains). According to the literature, the Delta de-loading method is the most practical and simple in application, however, the amount of power support is always vulnerable to wind speed conditions.

This paper considered four different worldwide real test systems which were investigated by four different papers. It is concluded that the penetration level and the system size have a clear influence on the achieved improvements in frequency response. Therefore, it is hard to set universal values for controllers' parameters (e.g. de-loading ratios and capacity factors) to assure that system inertia is not curtailed and maintain pre-wind penetration primary reserve.

Merging wind power and energy storage solutions and frequency associated frequency support methods is a feasible solution to overcome the risk of overlapping poor wind speed conditions with frequency events. In other words, the main frequency support procedure should come from wind farms, but when the wind speed conditions are very poor, storage mediums can provide the minimum acceptable response and compensate for low wind power capability. In addition, advances in wind speed measurement and forecasting technologies will improve the performance of support algorithms and mitigate wind energy wasting.

Finally, future grid codes should discriminate between onshore and offshore wind farms. They should also categorize wind farms based on the type of connection to the main grid (via the medium or high voltage AC or HVDC, which is used mainly for offshore wind farms). The 
expression wind farm should be replaced by wind power plant (i.e. wind farm behaving similarly to conventional generators) to reflect the necessity and ability of the provision of ancillary services, including frequency regulation, by wind power. This categorization has a great impact on wind farm obligations to frequency support.

\section{References}

[1] European Commission. Energy Roadmap 2050. Communication from the Commission to the European Parliament, the Council, the European Economic and Social Committee and the Committee of the Regions, Brussels. 2011. [online: https://ec.europa.eu/energy/sites/ener/files/documents/2012_energy_roadmap_2050_en_0.pdf ]

[2] European Commission. 2050 Energy strategy. Belgium2014 [online: https://ec.europa.eu/energy/en/topics/energy-strategy/2050-energy-strategy].

[3] European Wind Energy Association. EU Energy Policy to 2050: European Wind Energy Association; 2011.

[4] Schepers G, Pena A, Ely A, Palomares A, Attya A, Sieros G, et al. EERA DTOC calculation of scenarios. Denmark: The European Energy Research Alliance; 2015.

[5] Sykes B. The roadmap to 2020 and beyond: is offshore wind on track to drive costs down, local content up and cut carbon?. DONG Energy, 2016. [online: http://www.allenergy.co.uk/RXUK/RXUK_All-

Energy/2016/Presentations\%202016/Offshore\%20Wind\%201/Benj\%20Sykes\%20UPDATE D.pdf? $v=635993526284380223]$.

[6] Xu Z, Gordon M, Lind M, Ostergaard J. Towards a Danish Power System with 50\% Wind - Smart Grids Activities in Denmark. 2009 IEEE Power \& Energy Society General Meeting. 2009: 2171-8.

[7] Holttinen H, Orths AG, Eriksen PB, Hidalgo J, Estanqueiro A, Groome F, et al. Currents of Change. IEEE Power \& Energy Magazine. 2011; 9:47-59.

[8] European Network of Transmission System Operators for Electricity. Network Code on High Voltage Direct Current Connections and DC connected Power Park Modules. Brussels, 2014. 
[9] European Network of Transmission System Operators for Electricity. Network Code for Requirements for Grid Connection Applicable to all Generators. European Network of Transmission System Operators for Electricity; March 2013.

[10] Van Hulle F. Grid support services by wind and solar PV: a review of system needs, technology options, economic benefits and suitable market mechanisms-Synthesis report of the REserviceS project. REserviceS Deliverable D.7.1; July 2014.

[11] Attya AB. Wind enery penetration impact on grid frequency during normal operation and frequency deviations [PhD]. Darmstadt, Germany: Technical University of Dramstadt; 2014.

[12] Díaz-González F, Hau M, Sumper A, Gomis-Bellmunt O. Participation of wind power plants in system frequency control: Review of grid code requirements and control methods. Renewable and Sustainable Energy Reviews. 2014; 34:551-64.

[13] European Network of Transmission System Operators for Electricity. Supporting document for the network code on load-frequency control and reserve. 2013.

[14] Kundur P. Power System Stability and Control. New York: McGraw-Hill Inc.; 1994.

[15] A. Bergen, Vittal V. Power System Analysis. Second Edition ed. USA: Prentice Hall; 2000 .

[16] Díaz-González F, Sumper A, Gomis-Bellmunt O, Villafáfila-Robles R. A review of energy storage technologies for wind power applications. Renewable and Sustainable Energy Reviews. 2012; 16:2154-71.

[17] Jiang JN, Tang CY, Ramakumar RG. Control and Operation of Grid-Connected Wind Farms. Springer.

[18] Stock A. Augmented control for flexible operation of wind turbines [PhD]: University of Strathclyde; 2015.

[19] Kayikci M, Milanovic JV. Dynamic Contribution of DFIG-Based Wind Plants to System Frequency Disturbances. IEEE Transactions on Power Systems. 2009; 24:859-67.

[20] Akhmatov V. Analysis of Dynamic Behaviour of Electrical Power Systems with Large Amounts of Wind Energy [PhD]. Lyngby: Technical University of Denmark; 2003.

[21] T. Burton, D. Sharpe, N. Jenkins, Bossanyi E. Wind energy handbook: John Wiley \& Sons Ltd; 2001. 
[22] B. Fox, L. Bryans, D. Flynn, N. Jenckins, Milborrow D. Wind Power Integration: IET; 2007.

[23] Chang-Chien L-R, Yin Y-C. Strategies for Operating Wind Power in a Similar Manner of Conventional Power Plant. IEEE Transactions on Energy Conversion. 2009; 24:926-34.

[24] Ullah NR, Thiringer T, Karlsson D. Temporary primary frequency control support by variable speed wind turbines - Potential and applications. IEEE Transactions on Power Systems. 2008; 23:601-12.

[25] Keung P-K, Li P, Banakar H, Ooi BT. Kinetic Energy of Wind-Turbine Generators for System Frequency Support. IEEE Transactions on Power Systems. 2009; 24:279-87.

[26] Attya AB, Hartkopf T. Wind turbines support techniques during frequency drops Energy utilization comparison. AIMS Energy Journal. 2014; 2: 260-75.

[27] Miller NW, Clark K, Shao M. Frequency responsive wind plant controls: Impacts on grid performance. IEEE Power and Energy Society General Meeting, 2011.

[28] Morren J, de Haan SWH, Kling WL, Ferreira JA. Wind turbines emulating inertia and supporting primary frequency control. Power Systems, IEEE Transactions on. 2006;21:433-4. [29] Anaya-Lara O, Hughes FM, Jenkins N, Strbac G. Contribution of DFIG-based wind farms to power system short-term frequency regulation. IET Generation Transmission and Distribution. 2006; 153:164-70.

[30] Doherty R, Mullane A, Nolan G, Burke DJ, Bryson A, O'Malley M. An Assessment of the Impact of Wind Generation on System Frequency Control. IEEE Transactions on Power Systems. 2010; 25:452-60.

[31] Ruttledge L, Miller NW, O'Sullivan J, Flynn D. Frequency Response of Power Systems with Variable Speed Wind Turbines. IEEE Transactions on Sustainable Energy. 2012; 3:68391.

[32] B. G. Rawn, M. Gibescu, W. L. Kling. Kinetic Energy from Distributed Wind Farms: Technical Potential and Implications. IEEE Innovative Smart Grid Technologies Conference Europe. Sweden. 2010.

[33] Hafiz F, Abdennour A. Optimal use of kinetic energy for the inertial support from variable speed wind turbines. Renewable Energy. 2015; 80:629-43. 
[34] Lei W, Infield DG. Towards an Assessment of Power System Frequency Support From Wind Plant-Modeling Aggregate Inertial Response. IEEE Transactions on Power Systems. $2013 ; 28: 2283-91$.

[35] Attya ABT, Hartkopf T. Control and quantification of kinetic energy released by wind farms during power system frequency drops. IET Renewable Power Generation. 2013; 7:21024.

[36] Arani MFM, El-Saadany EF. Implementing Virtual Inertia in DFIG-Based Wind Power Generation. IEEE Transactions on Power Systems. 2013; 28:1373-84.

[37] Ekanayake J, Jenkins N. Comparison of the response of doubly fed and fixed-speed induction generator wind turbines to changes in network frequency. IEEE Transactions on Energy Conversion. 2004; 19:800-2.

[38] Valsera-Naranjo E, Sumper A, Gomis-Bellmunt O, Junyent-Ferré A, Martínez-Rojas M. Pitch control system design to improve frequency response capability of fixed-speed wind turbine systems. European Transactions on Electrical Power. 2011; 21:1984-2006.

[39] Margaris ID, Papathanassiou SA, Hatziargyriou ND, Hansen AD, Sorensen P. Frequency Control in Autonomous Power Systems With High Wind Power Penetration. IEEE Transactions on Sustainable Energy. 2012; 3: 189 - 99.

[40] Hiskens IA. Dynamics of Type-3 Wind Turbine Generator Models. IEEE Transactions on Power Systems. 2012; 27:465-74.

[41] Tarnowski GC, Kjaer PC, Sorensen PE, Ostergaard J. Variable Speed Wind Turbines Capability for Temporary Over-Production. IEEE Power \& Energy Society General Meeting. 2009.

[42] I. A. Gowaid, A. El-Zawawi, M. El-Gammal. Improved Inertia and Frequency Support from Grid-Connected DFIG Wind Farms. IEEE Power Systems Conference and Exposition (PSCE). USA. 2011.

[43] Vidyanandan KV, Senroy N. Primary frequency regulation by deloaded wind turbines using variable droop. IEEE Transactions on Power Systems. 2013; 28:837-46.

[44] M. Bhuiyan, Dinakar S. Comparing and Evaluating Frequency Response characteristics of Conventional Power Plant with Wind Power Plant [MSc]. Goteborg: Chalmers University of Technology; 2008. 
[45] de Almeida RG, Pecas Lopes JA. Participation of doubly fed induction wind generators in system frequency regulation. IEEE Transactions on Power Systems. 2007; 22:944-50.

[46] Attya AB, Hartkopf T. Wind turbine contribution in frequency drop mitigation - modified operation and estimating released supportive energy. IET Generation Transmission \& Distribution. 2014; 8:862-72.

[47] Tan Y, Meegahapola L, Muttaqi KM. A Suboptimal Power-Point-Tracking-Based Primary Frequency Response Strategy for DFIGs in Hybrid Remote Area Power Supply Systems. IEEE Transactions on Energy Conversion. 2016; 31:93-105.

[48] Chang-Chien L-R, Lin W-T, Yin Y-C. Enhancing Frequency Response Control by DFIGs in the High Wind Penetrated Power Systems. IEEE Transactions on Power Systems. 2011; $26: 710-8$.

[49] Z. Meng. An improved equivalent wind method for the aggregation of DFIG wind turbines. IEEE International Conference on Power System Technology (POWERCON). China. 2010.

[50] El Itani S, Annakkage UD, Joos G. Short-term frequency support utilizing inertial response of DFIG wind turbines. IEEE Power and Energy Society General Meeting. 2011.

[51] Gevorgian V, Zhang Y, Ela E. Investigating the Impacts of Wind Generation Participation in Interconnection Frequency Response. IEEE Transactions on Sustainable Energy. 2015; 6:1004-12.

[52] Wang Y, Delille G, Bayem H, Guillaud X, Francois B. High Wind Power Penetration in Isolated Power Systems-Assessment of Wind Inertial and Primary Frequency Responses. IEEE Transactions on Power Systems. 2013; 28:2412-20.

[53] Liu Y, Gracia J, King T, Liu Y. Frequency Regulation and Oscillation Damping Contributions of Variable-Speed Wind Generators in the U.S. Eastern Interconnection (EI). IEEE Transactions on Sustainable Energy. 2014; 6:951-58.

[54] Ye W, Bayem H, Giralt-Devant M, Silva V, Guillaud X, Francois B. Methods for Assessing Available Wind Primary Power Reserve. IEEE Transactions on Sustainable Energy. $2015 ; 6: 272-80$.

[55] Wilches-Bernal F, Chow JH, Sanchez-Gasca JJ. A Fundamental Study of Applying Wind Turbines for Power System Frequency Control. IEEE Transactions on Power Systems. 2016; 31: 1496-1505. 
[56] Attya AB, Hartkopf T. Wind farms dispatching to manage the activation of frequency support algorithms embedded in connected wind turbines. International Journal of Electrical Power \& Energy Systems. 2013;53:923-36.

[57] Baccino F, Conte F, Grillo S, Massucco S, Silvestro F. An Optimal Model-Based Control Technique to Improve Wind Farm Participation to Frequency Regulation. IEEE Transactions on Sustainable Energy. 2015; 6:993-1003.

[58] Díaz-González F, Hau M, Sumper A, Gomis-Bellmunt O. Coordinated operation of wind turbines and flywheel storage for primary frequency control support. International Journal of Electrical Power \& Energy Systems. 2015; 68:313-26.

[59] Bianchi FD, Dominguez-Garcia JL. Coordinated Frequency Control Using MT-HVDC Grids With Wind Power Plants. IEEE Transactions on Sustainable Energy. 2016;7:213-220.

[60] Hongzhi L, Zhe C. Contribution of VSC-HVDC to Frequency Regulation of Power Systems With Offshore Wind Generation. IEEE Transactions on Energy Conversion. 2015; 30:918-26.

[61] Rafferty J, Xu L, Wang Y, Xu G, Alsokhiry F. Frequency Support Using Multi-terminal HVDC Systems Based on DC Voltage Manipulation. IET Renewable Power Generation. 2016; recently accepted.

[62] Hansen AD, Altin M, Iov F. Provision of enhanced ancillary services from wind power plants-Examples and challenges. Renewable Energy. 2016; 97:8-18.

[63] Kusiak A, Zheng H, Song Z. Short-term prediction of wind farm power: a data mining approach. IEEE Transactions on Energy Conversion. 2009; 24:125-36.

[64] Ding Y, Wang P, Goel L, Loh PC, Wu Q. Long-term reserve expansion of power systems with high wind power penetration using universal generating function methods. IEEE Transactions on Power Systems. 2011; 26:766-74.

[65] Wang N, Johnson KE, Wright AD. Comparison of Strategies for Enhancing Energy Capture and Reducing Loads Using LIDAR and Feedforward Control. IEEE Transactions Control Systems. 2013; 21:1129-42.

[66] Eto, J.H., al e. Use of frequency response metrics to assess the planning and operating requirements for reliable integration of variable renewable generation. California: Lawrence Berkeley National Laboratory; 2010. 
[67] Vogler-Finck PJC, Früh W-G. Evolution of primary frequency control requirements in Great Britain with increasing wind generation. International Journal of Electrical Power \& Energy Systems. 2015; 73:377-88.

[68] Castro RMG, Ferreira L. A comparison between chronological and probabilistic methods to estimate wind power capacity credit. IEEE Transactions on Power Systems. 2001; 16:904909.

[69] Hulle FV, Pineda I, Wilczek P, al. e. Economic grid support services by wind and solar PV. Final publication of the REserviceS project. Belgium: European Wind Energy Association; 2014.

[70] Negnevitsky M, Nguyen DH, Piekutowski M. Risk Assessment for Power System Operation Planning With High Wind Power Penetration. IEEE Transactions on Power Systems. 2015; 30:1359-68.

[71] Teng F, Strbac G. Assessment of the Role and Value of Frequency Response Support From Wind Plants. IEEE Transactions on Sustainable Energy. 2016;7:586-95.

[72] Nelson RJ. Frequency-responsive wind turbine output control. Owner: Siemens Aktiengesellschaft US8301311 B2; 2012.

[73] Martinez-Garcia J. Frequency control. Owner: Vestas US 9341162 B2; 2016.

[74] The Commission for Energy Regulation. Rate of Change of Frequency (RoCoF) Modification to the Grid Code. Republic of Ireland. 2014.

[75] Tsili M, Papathanassiou S. A review of grid code technical requirements for wind farms. IET Renewable Power Generation. 2009; 3:308-32.

[76] O. Anaya-Lara, Ledesma P. D2.5 Procedure for Verification of Grid Code Compliance. University of Strathclyde; 2012.

[77] Burger B. Stromerzeugung aus Solar- und Windenergie 2014. Freiburg: Fraunhofer Institute for Solar Energy Systems; 2015.

[78] E. Ela, V. Gevorgian, P. Fleming, Y. Zhang, M. Singh, E. Muljadi, et al. Active Power Control from Wind Turbines: Bridging the Gaps. NREL; 2014.

[79] Parker MA, Anaya-Lara O. Cost and losses associated with offshore wind farm collection networks which centralise the turbine power electronic converters. IET Renewable Power Generation. 2013; 7:390-400. 
[80] Attya AB, Subramanian B. Impact of wind farms capacity factor and participation in frequency support - Reliability analysis. IEEE 5th International Conference Power Engineering, Energy and Electrical Drives. Latvia. 2015.

[81] Corcuera AD, Trilla L, Pujana-Arresse A, Gomis-Bellmunt O, Bianchi F, Landaluze J. Mechanical Load Analysis of PMSG Wind Turbines in Primary Frequency Regulation. European Wind Energy Association Conference. 2014.

[82] Junyent-Ferre A, Pipelzadeh Y, Green T. Blending HVDC-Link Energy Storage and Offshore Wind Turbine Inertia for Fast Frequency Response. IEEE Transactions on Sustainable Energy. 2015; 6:1059-66.

[83] Juan A. Martinez. Modeling and Characterization of Energy Storage Devices. IEEE Power and Energy Society General Meeting. Detroit Michigan. 2011.

[84] Liu Y, Du W, Xiao L, Wang H, Cao J. A Method for Sizing Energy Storage System to Increase Wind Penetration as Limited by Grid Frequency Deviations. IEEE Transactions on Power Systems. 2015; 31:729-37.

[85] Aghamohammadi MR, Abdolahinia H. A new approach for optimal sizing of battery energy storage system for primary frequency control of islanded Microgrid. International Journal of Electrical Power \& Energy Systems. 2014; 54:325-33.

[86] Attya AB. Integrating battery banks to wind farms for frequency support provisioncapacity sizing and support algorithms. AIP Journal of Renewable and Sustainable Energy. $2015 ; 7: 493-507$.

[87] Fathima AH, Palanisamy K. Battery energy storage applications in wind integrated systems - A review. International Conference on Smart Electric Grid (ISEG). 2014.

[88] E.ON Netz GmbH Tech. Rep. Grid Code: High and Extra High Voltage. Status: 1. Germany: E.ON Netz GmbH Tech. Rep.; 2006.

[89] Attya AB, Ali H, Hartkopf T. Frequency drops mitigation at high wind energy penetration by hydro-pumped storage - Capacity sizing. 17th IEEE Mediterranean Electro-technical Conference (MELECON). 2014.

[90] Attya AB, Hartkopf T. Utilizing stored wind energy by hydro-pumped storage to provide frequency support at high levels of wind energy penetration. IET Generation Transmission \& Distribution. 2015; 9:1485-97. 